IZA DP No. 9139

Multidimensional Affluence in Income and Wealth in the Eurozone:

A Cross-Country Comparison Using the HFCS

Sine Kontbay-Busun

Andreas Peichl

June 2015 


\title{
Multidimensional Affluence in Income and Wealth in the Eurozone: A Cross-Country Comparison Using the HFCS
}

\author{
Sine Kontbay-Busun \\ Dokuz Eylul University \\ Andreas Peichl \\ ZEW, University of Mannheim, \\ IZA and CESifo
}

\author{
Discussion Paper No. 9139 \\ June 2015
}

\author{
IZA \\ P.O. Box 7240 \\ 53072 Bonn \\ Germany \\ Phone: +49-228-3894-0 \\ Fax: +49-228-3894-180 \\ E-mail: iza@iza.org
}

Any opinions expressed here are those of the author(s) and not those of IZA. Research published in this series may include views on policy, but the institute itself takes no institutional policy positions. The IZA research network is committed to the IZA Guiding Principles of Research Integrity.

The Institute for the Study of Labor (IZA) in Bonn is a local and virtual international research center and a place of communication between science, politics and business. IZA is an independent nonprofit organization supported by Deutsche Post Foundation. The center is associated with the University of Bonn and offers a stimulating research environment through its international network, workshops and conferences, data service, project support, research visits and doctoral program. IZA engages in (i) original and internationally competitive research in all fields of labor economics, (ii) development of policy concepts, and (iii) dissemination of research results and concepts to the interested public.

IZA Discussion Papers often represent preliminary work and are circulated to encourage discussion. Citation of such a paper should account for its provisional character. A revised version may be available directly from the author. 


\section{ABSTRACT}

\section{Multidimensional Affluence in Income and Wealth in the Eurozone: A Cross-Country Comparison Using the HFCS*}

This paper applies multidimensional affluence measures to a new dataset on income and wealth in 15 Eurozone countries. We start our analysis by examining the income and wealth distributions separately for each country, and extend it to a multidimensional setting by considering the joint distribution of income and wealth. The results indicate that, with the exception of Cyprus, France, Italy and Slovenia, less than $10 \%$ of households are affluent in both income and net wealth. Investigating the joint distributions of income and net wealth confirms that France demonstrates a more homogenous distribution of richness among affluent households compared to other countries in the sample. Portugal demonstrates a higher concentration of richness in the hands of a few compared to the majority of other countries in the sample. The degree of countries' affluence rankings differs with respect to the measures of multidimensional affluence considered.

JEL Classification: D31, D63, I31

Keywords: top incomes, multidimensional measurement, richness, wealth, inequality

Corresponding author:

Andreas Peichl

Centre for European Economic Research (ZEW)

$\mathrm{L} 7,1$

68161 Mannheim

Germany

E-mail: peichl@zew.de

\footnotetext{
* The authors are grateful to Conchita D'Ambrosio, two anonymous referees as well as Nico Pestel and Martin Ungerer for valuable comments and suggestions on an earlier draft.
} 


\section{INTRODUCTION:}

Inequality at the top of the distribution received considerable interest both in the academic literature (see Atkinson et al. (2011) for an overview) as well as in public debate. So far, and in contrast to poverty ${ }^{1}$, affluence has mostly been analyzed for a single dimension, typically income or, to a lesser extent, wealth. ${ }^{2}$ Multidimensional analyses are relatively scarce. ${ }^{3}$ An exception is Peichl and Pestel (2013a), who develop a measure of multidimensional affluence based on the unidimensional measures of Peichl, et al. (2010). ${ }^{4}$

In this study we apply Peichl and Pestel's (2013a) multidimensional affluence measures to a new dataset on income and wealth in 15 Eurozone countries - the Household Finance and Consumption Survey (HFCS). ${ }^{5}$ The first wave of HFCS has become available only recently (Eurosystem Household Finance and Consumption Network, 2013a,b). Hence, the literature analyzing the income and wealth structure of the HFCS data is limited and mostly concerns the wealth distribution. Fessler et al. (2014) have studied the relationship between household structures and cross-country differences in wealth distribution. Vermeulen (2014) combined HFCS and the US Survey of Consumer Finances (SCF) with data from the Forbes World's Billionaires list in order to compare and contrast the structure of the top tail of the wealth distribution in the Eurozone and in the US. Arrondel et al. (2014) estimate the predictive power of a household's rank in the income distribution on the basis of its ranking in the wealth distribution. Therefore, our study is the first work to consider the joint distribution of income and wealth through multidimensional affluence measures for such a large range of European countries. As the HFCS includes harmonized variables across all countries in the sample, it increases the cross-country comparability for the Eurozone and, therefore, provides an invaluable opportunity to compare and contrast the multidimensional affluence of Euro area countries in a multidimensional setting.

Our results indicate a weak correlation between income and net wealth and a less than perfect correlation between the rankings of households within the marginal distributions of both dimensions. With the exception of France, Italy and Slovenia, less than $10 \%$ of households

\footnotetext{
${ }^{1}$ See, e.g., Atkinson (2003), Bourguignon and Chakravarty (2003), Alkire and Foster (2011) Decancq and Ooghe (2010), Decancq and Lugo (2011a,b), among others.

${ }^{2}$ See, e.g., Atkinson (2005), Piketty (2005), Saez (2005), Piketty and Saez (2006), Atkinson and Piketty (2007), Roine and Waldenström (2008), Roine et al. (2009) and Roine and Waldenström (2011).

${ }^{3}$ See, e.g., Kopczuk and Saez (2004), Jenkins and Jäntti (2005) and Waldenström (2009).

${ }^{4}$ Peichl and Pestel (2013b) considered health and overall life satisfaction in addition to income while measuring the well-being at the top of the distribution in Germany.

${ }^{5}$ For the remainder of this paper, the 15 euro area countries included in the first wave of the HFCS are referred to as the Eurozone.
} 
are affluent in both income and net wealth distribution. The degree of countries' affluence rankings differ for different measures of multidimensional affluence. Joint distributions of income and net wealth show that France demonstrates a more homogenous distribution of richness among affluent households compared to other countries in the sample. Portugal demonstrates a higher concentration of richness in the hands of a few compared to the majority of other countries in the sample.

The paper is organized as follows. In Section 2, we describe the dataset and the methodology. The dimensions, descriptive statistics and empirical results are presented in Section 3. Section 4 provides robustness checks and Section 5 concludes.

\section{DATA and METHODOLOGY}

\subsection{HFCS DATA and CROSS-COUNTRY COMPARABILITY}

We use the first wave of the Household Finance and Consumption Survey (HFCS) which was released in April 2013. The survey contains data on households' finances and consumption for 62,500 households from 15 of the 18 euro area countries ${ }^{6}$ with sample sizes ranging from 343 for Slovenia to 15,006 for France. In an effort to improve the quality of estimates based on HFCS data, the HFCS harmonize the survey output of the participating countries a priori, by giving the countries the flexibility to formulate their own questions based on a common template questionnaire provided. The sampling design, weighting, imputation and variance estimation are also harmonized across countries.

The HFCS data network applied a multiple imputation method to overcome the item nonresponse problem, and used population weights in order to adjust for the unit non-response problem (i.e. respondent's refusal to participate in the survey): (i) The multiple imputation method produces 5 different imputed datasets by estimating the missing items from several covariates. $^{7,8}$ Given that there are very few missing observations for Italy and no nonresponse items for Finland, the multiple imputation procedure is not applied to these countries. (ii) The sampling weights are equal to the inverse of the probability of being sampled. It is only in the case of Slovakia that quota sampling is applied for the first wave.

\footnotetext{
${ }^{6}$ Estonia, Ireland and Latvia did not participate in the first wave of the survey.

${ }^{7}$ Multiple imputation method avoids inefficiencies in estimation imposed by singly-imputed data and allows standard techniques to be used for complete data. It also improves the comparability of the data across countries. ${ }^{8}$ In order to incorporate the information from all five implicates we combined the five imputed set as one complete dataset and then obtained the point estimates of the parameters we are interested in (i.e. mean and median income and wealth) as well as our richness measures by using the population weights. The results are cross checked by first analyzing each of the five datasets separately and then averaging the results across implicates. We have confirmed that the results from these two approaches match.
} 
The households in the survey are weighted such that the sum of the weights for all sampled households of a country approximates the total number of households in the population of that country. ${ }^{9}$ The number of sampled households and total number of households in the population are provided in Table 1 . Households in Germany constitute approximately 29\% of the total number of households in the Eurozone. Germany is followed by France, Italy and Spain. The population shares of households in Cyprus, Slovenia, Luxembourg and Malta are less than $1 \%$. The small sample size for Slovenia indicates that the results for this country may not be fully representative. Malta and Luxembourg are two further countries with small sample sizes.

Table 1. Population Shares

\begin{tabular}{cccc}
\hline Country & $\begin{array}{c}\text { Sampled } \\
\text { Households }\end{array}$ & $\begin{array}{c}\text { Number of Households in } \\
\text { Population }\end{array}$ & $\begin{array}{c}\text { Household } \\
\text { Population Shares }\end{array}$ \\
\hline AT & 2,380 & $3,773,956$ & 2.73 \\
BE & 2,327 & $4,692,601$ & 3.40 \\
CY & 1,237 & 303,242 & 0.22 \\
DE & 3,565 & $39,673,000$ & 28.72 \\
ES & 6,197 & $17,017,706$ & 12.32 \\
FI & 10,989 & $2,531,500$ & 1.83 \\
FR & 15,006 & $27,860,408$ & 20.17 \\
GR & 2,971 & $4,114,150$ & 2.98 \\
IT & 7,951 & $23,817,962$ & 17.24 \\
LU & 950 & 186,440 & 0.13 \\
MT & 843 & 143,677 & 0.10 \\
NL & 1,301 & $7,386,144$ & 5.35 \\
PT & 4,404 & $3,932,010$ & 2.85 \\
SI & 343 & 777,777 & 0.56 \\
SK & 2,057 & $1,911,664$ & 1.38 \\
\hline
\end{tabular}

HFCS adjusted the population weights not only to account for the unit non-response problem, but also to ensure oversampling of wealthy households at the top of the wealth distribution.. Various oversampling strategies are employed for all countries except Italy, Malta, the Netherlands and Slovakia. These strategies differ from country to country depending on the

\footnotetext{
${ }^{9}$ We use the weights for all empirical analyses in this study.
} 
available data and country-specific features of each participant member of the Eurozone. ${ }^{10}$ Thus, the differences between countries in terms of the oversampling strategies used, may have an influence on wealth comparisons.

Despite these efforts to produce comparable data, there are some methodological differences that must be considered while making cross-country comparisons with HFCS data. First of all, with a few exceptions, all fieldwork was conducted in late 2010 or in early $2011{ }^{11}$ Exceptions include Spain, where the fieldwork period is 2008-2009, France, where fieldwork was carried out between late 2009 and early 2010, Greece, where fieldwork was completed in 2009. Fessler and Shurz (2013) argue that because wealth is a stock variable and stable over time, the differences in field periods are expected to have a negligible influence on wealth measures. Moreover, since the field periods correspond to the early years of the global financial crisis, we believe that deleveraging of households following these crisis should not be a great concern for the comparability.

There are several papers which discuss the comparability of the HFCS data across countries. For instance, Andreasch and Linder (2014) compare and contrast the HFCS data from Austria and the data from its national accounts. They find that the HFCS successfully identifies the basic deposit patterns while the total wealth estimations might be biased downward. Their simulation of the top savings ranges indicates that measures such as the Gini coefficient, arithmetic mean, median and percentiles obtained from HFCS provides at least a lower bound for their true values while the statistics like median and percentiles are mainly robust. Honkkila and Kavonius (2013) link the micro and macro data sources for Finland, Italy and the Netherlands in order to compare and contrast the wealth components from HFCS and the national accounts. Fessler and Shurz (2013) discuss the cross-country comparability of HFCS results whilst placing a focus on net wealth distribution. They are in favor of examining the complete distribution of wealth rather than ranking countries according to their mean or median of net wealth distribution. Tiefensee and Grabka (2014) provide a detailed analysis of the cross-country differences of the survey techniques applied in HFCS and discuss the methodological constraints of HFCS data on the cross-country comparability. All of these studies agree that HFCS provides valuable information, particularly for cross-country comparison of wealth distribution in the Eurozone. However, these studies also highlight issues relevant to the cross-country comparability of the HFCS. In the following, we will

\footnotetext{
${ }^{10}$ See Appendix A.1.4 for the list of countries that applied oversampling strategies.

11 The differences in the fieldwork and reference periods are listed in Table A.1 in the Appendix.
} 
summarize the comparability problems which arise from use of the HFCS, and which are indicated in the aforementioned literature: (i) Survey Mode: The survey modes are largely consistent across countries. Exceptions include Finland, which obtains most of the information from register data and the Netherlands, which conducts respondent-administrated interviews. Compared to face-to-face interviews, this data collection method may result in imprecise answers being given in response to the survey questions (Honkkila and Kavonius (2013)). Tiefensee and Grabka (2014) argue that the major difference between the HFCS data for Finland and for other countries, is that the Finish survey does not collect data on certain core variables. This results in an underestimation of net worth data. (ii) Unit Response Rates: Tiefensee and Grabka (2014) suspect that the survey data for Finland, France, Italy, the Netherlands and Spain differ from the data available for other countries in the sample as these countries have used already existing wealth surveys. As a result, the surveys in these countries have a panel structure, while in other countries households are not familiar with the survey and the interviewer. ${ }^{12}$ (iii) Survey weights: The comparison of the weighted micro data with national accounts indicates that for Belgium and Slovenia HFCS data capture more than $90 \%$, while the Netherlands' HFCS data capture only slightly more than $50 \%$ of the national accounts' wealth. ${ }^{13}$ Honkkila and Kavonius (2013) found that total financial wealth (liability) of Finland covers 39\% (90\%) of financial wealth in national accounts, while this rate is $22 \%$ (45\%) for Italy and 30\% (92\%) for the Netherlands. ${ }^{14}$ (iv) Oversampling: Tiefensee and Grabka (2014) state that the relevance of oversampled households cannot be measured. This is due to the fact that the HFCS does not distinguish oversampled households from the remainder of the sample. The effective oversampling rates for the top $10 \%$ indicate that the wealth inequality measures are expected to be biased downward for countries that oversample only large cities (Austria, Portugal, and Slovenia) and for countries that do not oversample at all (Italy, Malta and Slovakia). ${ }^{15}$ France and Spain use wealth information as a basis for oversampling and high effective oversampling rates indicate, that of all participating

\footnotetext{
${ }^{12}$ Fessler and Shurz (2013) note that households in Spain and Austria were extensively re-contacted in order to confirm responses of households that seemed implausible. In Germany, France, Luxembourg and Slovakia, however, it was not possible to re-contact households in order to correct mistakes.

${ }^{13}$ Note that Fessler and Shurz (2013) criticize the efforts made to compare the household based micro data sources with countries' national accounts as they believe that these data sources serve different objectives with different reference populations.

${ }^{14}$ The coverage rate of total financial wealth of HFCS in comparison to national accounts increases to $62 \%$ for Finland, 27\% for Italy and 47\% for Netherlands when pensions, unquoted shares and other assets are excluded from the financial wealth comparison as their definitions are neither identical or similar in national accounts nor in the HFCS.

${ }^{15}$ The Netherlands also did not apply oversampling, however, it has a high effective oversampling rate. (see Appendix A.1.4 for a definition of effective oversampling rates by country).
} 
countries, these are the two countries with the most appropriate oversampling techniques. Fessler and Shurz (2013) estimate that around 0.5\% of Austrian households at the very top of the wealth distribution is entirely missing (v) Item non-response: The number of covariates used for imputation varies considerably across countries suggesting that precision of the imputed items may also vary across countries. The relevance of the imputed variables is greater for gross financial wealth than for gross real wealth and gross income (ECB, 2013a). The details of the number covariates used in the imputation of important balance sheet and income variables and the relevance of the imputed variables for Gross Real Wealth, Gross Financial Wealth and Gross income are listed in Table A.1.2 and Table A.1.3 in the appendix.

\subsection{METHODOLOGY}

We use the dual cut-off method proposed by Peichl and Pestel (2013a) in order to measure the multidimensional well-being at the top of the joint income and wealth distribution in the Eurozone countries. The initial cut-off is set in order to enable identification of dimensionspecific, well-off households. The households, whose achievements in a specific dimension exceed the dimension specific threshold set by the first cut-off, are considered to be affluent with respect to that given dimension. The second cut-off is set in order to define the minimum number of dimensions in which a household must be well-off in order that it can be deemed multidimensional affluent.

More specifically, we measure the multidimensional affluence of a population with $\mathrm{n}$ households and $\mathrm{d} \geq 2$ dimensions. The achievement of household $i \epsilon\{1, \ldots, n\}$ in dimension $j \in\{1, \ldots, d\}$ is denoted by $y_{i j}$. Households, whose achievements in dimension $\mathrm{j}$ exceed the dimension specific initial cut-off value $\left(\gamma_{j}\right)$, are recorded by an indicator function $\theta_{i j}$. The indicator function takes the value one if $y_{i j}>\gamma_{i j}$ and zero if otherwise. The total number of dimensions in which household $i$ is well-off is denoted as $c_{i}=\sum_{j} \theta_{i j}$. If we denote the second cut-off as an integer $k \in\{1, \ldots, d\}$, then the multidimensional affluent households can be recorded by an indicator function $\varphi_{i}(k)$. The indicator function takes the value 1 for households which are well-off in at least $k$ dimensions (i.e. $c_{i} \geq k$ ) and 0 if otherwise.

The total number of affluent households in the population is $s(k)=\sum_{i} \varphi_{i}(k)$. The focus axiom suggests that a measure of richness should disregard the achievements of households which are not well-off in at least $k$ dimensions. Hence, for households which are unable to attain affluence in at least $k$ dimensions, $c_{i}(k)$ is set to zero. Formally: 


$$
c_{i}(k)=\left\{\begin{array}{l}
c_{i} \text { if } \varphi_{i}(k)=1 \\
0 \text { if } \varphi_{i}(k)=0
\end{array}\right.
$$

Based on these definitions, Peichl and Pestel (2013a) define several measures of multidimensional affluence. The fraction of affluent households in the total population, i.e., the headcount ratio is given by:

$$
H R(k)=\frac{s(k)}{n}
$$

The average affluence share is defined as the ratio of affluence counts to the maximum number of affluence counts that would be observed when all affluent households were affluent in all dimensions:

$$
A A S(k)=\frac{\sum_{i} c_{i}(k)}{s(k) \cdot d}
$$

However, the headcount ratio does not satisfy the property of dimensional monotonicity, as the value of $H R(k)$ does not change when a multidimensionally affluent household becomes (or is no longer) affluent in any given dimension. Therefore, a dimension-adjusted headcount ratio that is sensitive to the changes in households' affluence counts, can be defined by multiplying $H R(k)$ and $A A S(k)$ :

$$
R_{H R}^{M}(k)=H R(k) \cdot A A S(k)=\frac{\sum_{i} c_{i}(k)}{n \cdot d}
$$

The dimension-adjusted headcount ratio is defined as the proportion of the total number of affluence counts to the maximum number of affluence counts attainable, if every individual were affluent in every dimension.

The dimension-adjusted headcount ratio, however, does not satisfy the monotonicity condition. It is a measure of multidimensional affluence which is unaffected by an increase or a decrease in $y_{i j}$ - the achievement of individual $i$ in dimension $j$. Therefore, following Peichl and Pestel (2013), we construct dimension-adjusted multivariate affluence measures that take the intensity of affluence into account. In order to set up the dimension adjusted multivariate affluence measures, we first need to measure the intensity of affluence in each dimension. The general idea, as developed in the axiomatic approach by Peichl et al. (2010), is very similar to the FGT poverty measures (Foster et al., 1984). The key difference between poverty and 
richness, however, is that the transfer axiom of poverty measurement ${ }^{16}$ can be translated to a measurement of richness in two different ways (Peichl et al., 2010):

- Transfer axiom T1 (concave): a richness index should increase when a rankpreserving progressive transfer takes place between two rich individuals.

- Transfer axiom T2 (convex): a richness index should decrease when a rankpreserving progressive transfer takes place between two rich individuals.

In view of the definitions provided for these two opposite axioms, the following question may be asked: "Should an index of richness increase if (i) a billionaire gives an amount $x$ to a millionaire, or (ii) if the millionaire gives the same amount $x$ to the billionaire?” This question cannot be answered without moral judgement; see the discussion in Peichl et al. (2010) for more details concerning the pros and cons of the two approaches. ${ }^{17}$ The convex and concave transfer axioms suggest that the intensity of affluence ${ }^{18}$ can be measured as follows:

$$
\begin{aligned}
& \Theta^{\alpha}=\left[\left(\frac{y_{i j}-\gamma_{j}}{\gamma_{j}}\right)_{+}^{\alpha}\right]_{n \times d} \text { for } \alpha \geq 1 \\
& \Theta^{\beta}=\left[\left(1-\left(\frac{\gamma_{j}}{y_{i j}}\right)^{\beta}\right)_{+}\right]_{n \times d} \text { for } \beta>0
\end{aligned}
$$

Here, $\Theta^{\alpha}$ and $\Theta^{\beta}$ are matrices that contain convex and concave measures of intensity of affluence associated with each dimension, respectively. As is indicated by the '+' subscript, the entries of the matrices must be non-negative. As the value of the convex sensitivity parameter $\alpha$ increases, greater emphasis is placed on a more concentrated affluence. For the concave measure of intensity, however, the smaller value of parameter $\beta$ results in greater emphasis on more intense affluence. ${ }^{19}$

\footnotetext{
${ }^{16}$ A poverty index satisfies the transfer axiom if the index decreases when a rank-preserving progressive transfer from a poor individual to an even poorer individual takes place.

${ }^{17}$ The concave measurement approach is in line with the "polarization view", and thus, concerned with the homogeneity of the distribution among rich, while the convex measure focuses on the concentration of richness in the hands of a few as suggested by the "inequality view" (Peichl et. al., 2010).

${ }^{18}$ Note that the convex measure resembles a translation of the FGT poverty measure to richness. For $\alpha=1$ it measures an affluence gap and for $a=2$ it measures the affluence intensity.

${ }^{19}$ Examples are taken from Peichl et. al. (2010, p.606) Case $1: X_{1}=(5,5,5,11,11)$ vs. $Y_{1}=(5,5,5,100,100)$ and Case 2: $X_{2}=(5,5,5,11,9989)$ vs. $Y_{2}=(5,5,5,1000,9000)$. In both cases, the ratio of affluent households in all populations is the same (ie. $\operatorname{HR}(\mathrm{X})=\mathrm{HR}(\mathrm{Y})$ ). In the first case (the intensity of) affluence is higher in population $\mathrm{Y}$ compared to population $X$ for both convex and concave measures (ie. $\boldsymbol{R}_{\boldsymbol{\alpha}, \boldsymbol{\beta}=\mathbf{2}}^{\boldsymbol{M}}(\boldsymbol{Y})>\boldsymbol{R}_{\boldsymbol{\alpha}, \boldsymbol{\beta}=\mathbf{2}}^{\boldsymbol{M}}(\boldsymbol{X})$ ). In the second case, “concave affluence” (homogeneity among the rich) is higher in population Y (ie. $\boldsymbol{R}_{\boldsymbol{\beta}=\mathbf{2}}^{\boldsymbol{M}}(\boldsymbol{Y})>\boldsymbol{R}_{\boldsymbol{\beta}=\mathbf{2}}^{\boldsymbol{M}}(\boldsymbol{X})$ ) while “convex affluence" (inequality among the rich) is higher in population X (ie. $\boldsymbol{R}_{\boldsymbol{\alpha}=\mathbf{2}}^{\boldsymbol{M}}(\boldsymbol{Y})<\boldsymbol{R}_{\boldsymbol{\alpha}=\mathbf{2}}^{\boldsymbol{M}}(\boldsymbol{X})$ ).
} 
As mentioned before, the focus axiom suggests that these matrices should contain only information pertaining to affluent individuals. Thus, the rows which correspond to nonaffluent individuals are replaced with zero whenever it holds that $\varphi_{i}(k)=0$.

Hence, the dimension adjusted multivariate affluence measure reads as follows:

$R_{l}^{M}(k)=H R(k) \cdot A A S(k) \cdot \frac{\sum_{j=1}^{d}\left|\theta_{j}^{l}(k)\right|}{\sum_{i} c_{i}(k)}=\frac{\sum_{j=1}^{d}\left|\theta_{j}^{l}(k)\right|}{n \cdot d}$ for $l \in\{\alpha, \beta\}$

$\left|\theta_{j}^{l}(k)\right|$ represents the sum of concave and convex intensity measures for all individuals within each dimension. The proportional contribution of each dimension to the dimensionadjusted multivariate affluence measure can therefore be represented as follows:

$$
\pi_{j}^{l}(k)=\frac{\left|\theta_{j}^{l}(k)\right|}{\sum_{j=1}^{d}\left|\theta_{j}^{l}(k)\right|}
$$

\section{EMPIRICAL RESULTS}

\subsection{DIMENSIONS and DESCRIPTIVES}

In our calculations, the units of analysis are households. We use HFCS' aggregations of total household gross income and household net wealth. Total gross household income is the sum of employee income, self-employment income, transfer income (income from pensions and regular social transfers) and capital income (gross rental income from real estate property, gross income from financial transfers, gross income from private business other than selfemployment and gross income from other sources). ${ }^{20}$ Household net wealth is defined as the difference between the aggregate household assets, excluding public and occupational pension wealth, and the total outstanding household liabilities. ${ }^{21}$ We apply the square root equivalence scale to all income and net wealth observations.

\footnotetext{
${ }^{20}$ The standard in the empirical literature on income inequality is to use total disposable income as an income measure. Because disposable income is not available in HFCS, we use total gross household income in our calculations. We acknowledge that the gross income can vary from country to country due the contribution of the pension entitlements and other savings and benefits. Thus, we recalculated all of our measures by defining income only as the sum of employee and self-employment income (i.e. excluding transfer and capital income from calculations) in order to see the effects of the differences in transfer income and capital income between countries on our calculations. We also recalculated our richness measures by excluding capital income (which might be seen as a proxy for wealth). We observe that the ordering of countries according to various richness measures, and hence, our conclusions, do not change. We therefore do not provide the results of this alternative income definition here. These can, however, be provided to the reader upon request.

${ }^{21}$ In HFCS' derived statistics, pensions are considered as a source of income and are therefore included in income definition rather than in wealth. However, there might be important differences between countries in terms of (Public) pension wealth. The HFCS survey only collects information on current termination value of (funded) private pension wealth and excludes wealth from public pension schemes. Given that pension wealth is
} 
Cut-offs. Following Peichl and Pestel (2013a), and in order to identify the well-off subpopulation, we set the initial cut-off, the one dimensional richness line, at the $80 \%$ quantile of each distribution. ${ }^{22}$ Table 2 presents descriptive statistics of income and wealth dimensions and their corresponding cut-off levels. The mean income ranges between 13,000 Euros in Slovakia to 83,657 Euros in Luxembourg. In both countries, for both income and wealth, the median is lower than the mean, thus indicating inequality.

Table 2: Descriptive Statistics and Cut-offs

\begin{tabular}{|c|c|c|c|c|}
\hline Country & Dimension & Mean & Median & Cut-off $(*)$ \\
\hline \multirow{2}{*}{$\mathbf{A T}$} & Income & 43,929 & 32,245 & 60,221 \\
\hline & Net Wealth & 265,033 & 76,360 & 311,200 \\
\hline \multirow{2}{*}{ BE } & Income & 49,536 & 33,600 & 69,000 \\
\hline & Net Wealth & 338,647 & 206,000 & 483,670 \\
\hline \multirow{2}{*}{$\mathbf{C Y}$} & Income & 43,255 & 32,400 & 60,320 \\
\hline & Net Wealth & 670,910 & 265,500 & 771,000 \\
\hline \multirow{2}{*}{ DE } & Income & 43,531 & 32,500 & 61,000 \\
\hline & Net Wealth & 195,170 & 51,500 & 261,000 \\
\hline \multirow{2}{*}{ ES } & Income & 31,329 & 24,800 & 43,000 \\
\hline & Net Wealth & 291,352 & 182,753 & 387,433 \\
\hline \multirow{2}{*}{ FI } & Income & 45,141 & 36,257 & 65,195 \\
\hline & Net Wealth & 161,534 & 85,750 & 262,914 \\
\hline \multirow{2}{*}{ FR } & Income & 36,918 & 29,214 & 49,161 \\
\hline & Net Wealth & 233,399 & 115,808 & 328,784 \\
\hline \multirow{2}{*}{ GR } & Income & 27,661 & 22,014 & 39,654 \\
\hline & Net Wealth & 147,757 & 102,000 & 220,000 \\
\hline \multirow{2}{*}{ IT } & Income & 34,344 & 26,260 & 48,333 \\
\hline & Net Wealth & 275,205 & 173,500 & 375,500 \\
\hline \multirow{2}{*}{$\mathbf{L U}$} & Income & 83,657 & 65,000 & 114,900 \\
\hline & Net Wealth & 710,092 & 398,473 & 887,136 \\
\hline \multirow{2}{*}{ MT } & Income & 26,443 & 21,641 & 39,353 \\
\hline & Net Wealth & 365,988 & 216,938 & 455,293 \\
\hline
\end{tabular}

highly relevant for many countries, a fully comparable wealth distribution is not possible. Pension wealth in HFCS data, for example, corresponds only to $21 \%$ of the pension wealth captured in National accounts of Finland, while this rate is $16 \%$ for Italy and $24 \%$ for the Netherlands (Kavonius and Honkkila (2013))

${ }^{22}$ We prefer to present the results for top 90\% and top 99\% quantiles in the Appendix (see tables A.2 through A.8). The reader should bear in mind that the impact of heterogeneities in the survey methodology between countries are expected to be greater as the top shares of income and wealth get narrower. 


\begin{tabular}{clccc} 
NL & Income & 45,792 & 40,484 & 64,348 \\
& Net Wealth & 170,244 & 103,711 & 305,123 \\
PT & Income & 20,310 & 14,650 & 28,004 \\
& Net Wealth & 152,920 & 75,300 & 188,486 \\
\multirow{2}{*}{ SI } & Income & 22,334 & 18,150 & 33,900 \\
& Net Wealth & 148,736 & 100,433 & 237,500 \\
\multirow{2}{*}{ SK } & Income & 13,467 & 11,200 & 18,376 \\
& Net Wealth & 79,656 & 61,200 & 107,670 \\
\hline
\end{tabular}

Source: HFCS, authors' own calculations.

(*) The cut-off values for the top $90 \%$ and $99 \%$ quantiles as well as for the PPP adjusted income and net wealth are presented in Appendix A.2.

In regard to mean net wealth, we observe that Slovakia has, once again, the lowest value in the sample, whilst Luxembourg has the highest. The most skewed net wealth distribution is observed in Austria and Germany, where the mean net wealth is equal to more than triple the median net wealth.

Differences in household composition in terms of criteria such as age, education and size, are expected to play a significant role, resulting in differences in income and wealth distributions between countries. D’Alessio et al. (2013) briefly discuss the importance of household structure when assessing the cross-country wealth distribution. Considering that there are more single or two person households in northern European countries than in southern and eastern European countries, cross-country distributional differences are to be expected and should be kept in mind when interpreting results.

\subsection{WELL-OFF COUNTS}

Considering the cut-off values presented in Table 2, the distribution of the number of affluent households across the Eurozone countries is presented in Table 3. The first column lists the percentage of households which are affluent in one or in both dimensions. The second column lists the number of households in the population of the corresponding country, which are affluent in exactly one dimension. The first column shows that approximately $70 \%$ of the population in each country is not well-off in any dimension. The third column also presents the percentage of households affluent in both dimensions. It is only in France, Italy and Slovenia that (slightly) more than $10 \%$ of households are affluent in both dimensions. This value is lowest in the Netherlands. It is also worth noting that the Netherlands is also the 
country with the highest percentage of households which are well-off in at least one dimension (33\%). This suggests that the correlation between income and wealth is weakest for the Netherlands.

Table 3. Headcount Ratios

\begin{tabular}{|c|c|c|c|}
\hline Country & $\begin{array}{l}\text { Well-off in at } \\
\text { least one } \\
\text { dimension }\end{array}$ & $\begin{array}{l}\text { Well-off in } \\
\text { exactly one } \\
\text { dimension }\end{array}$ & $\begin{array}{c}\text { Well-off in } \\
\text { both } \\
\text { dimensions }\end{array}$ \\
\hline AT & 30.33 & 20.67 & 9.66 \\
\hline $\mathrm{BE}$ & 32.46 & 24.98 & 7.48 \\
\hline CY & 29.88 & 19.94 & 9.94 \\
\hline $\mathrm{DE}$ & 29.96 & 20.00 & 9.96 \\
\hline $\mathrm{ES}$ & 30.42 & 21.14 & 9.28 \\
\hline FI & 31.02 & 22.05 & 8.98 \\
\hline FR & 29.60 & 19.21 & 10.39 \\
\hline GR & 30.91 & 21.92 & 9.00 \\
\hline IT & 29.59 & 19.25 & 10.34 \\
\hline LU & 30.24 & 20.51 & 9.73 \\
\hline MT & 32.88 & 25.80 & 7.08 \\
\hline NL & 33.35 & 26.75 & 6.60 \\
\hline $\mathrm{PT}$ & 30.37 & 20.76 & 9.61 \\
\hline SI & 29.59 & 19.25 & 10.35 \\
\hline SK & 32.12 & 24.28 & 7.84 \\
\hline
\end{tabular}

\subsection{ONE DIMENSIONAL AFFLUENCE}

In this section we present our results for one dimensional measures of well-being (i.e. $d=1$ ) by considering the income and wealth distributions separately (following Peichl et al., 2010). Table 4 presents the values of dimension-adjusted univariate well-being measures for income and Table 5 presents the results for wealth. The left-hand blocks in Tables 4 and 5 display the results for the convex univariate affluence measure (with sensitivity parameter $\alpha$ ranging from 1 to 3) whilst the right-hand blocks display the results for the concave univariate affluence measure for different values of sensitivity parameter $\beta$. Note that when $\alpha=1$, the convex measure of dimension adjusted univariate affluence can be interpreted, by definition, as the 
population average of the percentage deviation of affluent households' achievements from the top $80 \%$ quantile cut-off (i.e. it measures the “affluence gap”). ${ }^{23}$ When $\beta=1$, however, the concave measure of dimension adjusted univariate affluence gives a population average for affluent households' achievements which lies above the dimension-specific threshold, as a fraction of their own achievement.

Income. Considering the dimension adjusted univariate affluence measures with respect to income (shown in Table 4 and visualized in Figure 1), the highest convex univariate measure is observed for Belgium (0.173) and the lowest for the Netherlands (0.074), when $\alpha$ is equal to 1. This derives from the fact that affluent households in Belgium earn on average $17 \%$ more than the cut-off value, whilst in the Netherlands, the average percentage deviation of income from the threshold value is approximately $7 \%$. Whilst the differences between the countries are moderate when $\alpha=1$, the convex measure of univariate affluence increases as the sensitivity parameter $\alpha$ increases. This is the case for all sampled countries except the Netherlands. The most significant jump in the affluence measure is observed in Spain, Belgium and France for higher values of $\alpha$. In addition, these countries have the highest convex dimension adjusted univariate affluence measures when $\alpha>1$.

The difference between the countries are more moderate in regard to the concave dimension adjusted univariate affluence measure of income for all values of sensitivity parameter $\beta$. Where $\beta=1$, the highest value of the concave measure of dimension adjusted univariate affluence with respect to income, is again observed for Portugal (0.067) and the lowest is observed for the Netherlands (0.046). We do not observe a great change in the value of the concave affluence measure as $\beta$ increases. For $\beta>1$, the highest values of the concave measure are observed for Portugal and Slovenia and the lowest values are observed for Malta and for the Netherlands.

\footnotetext{
${ }^{23}$ Note that because our chosen definition of being "rich" corresponds to the top $20 \%$ of income and wealth distribution in each country, the headcount ratio (percentage of rich people) is equal to $20 \%$ in the univariate case for all countries in the sample.
} 
Figure 1. Comparison of One Dimensional Measures of Affluence for Income

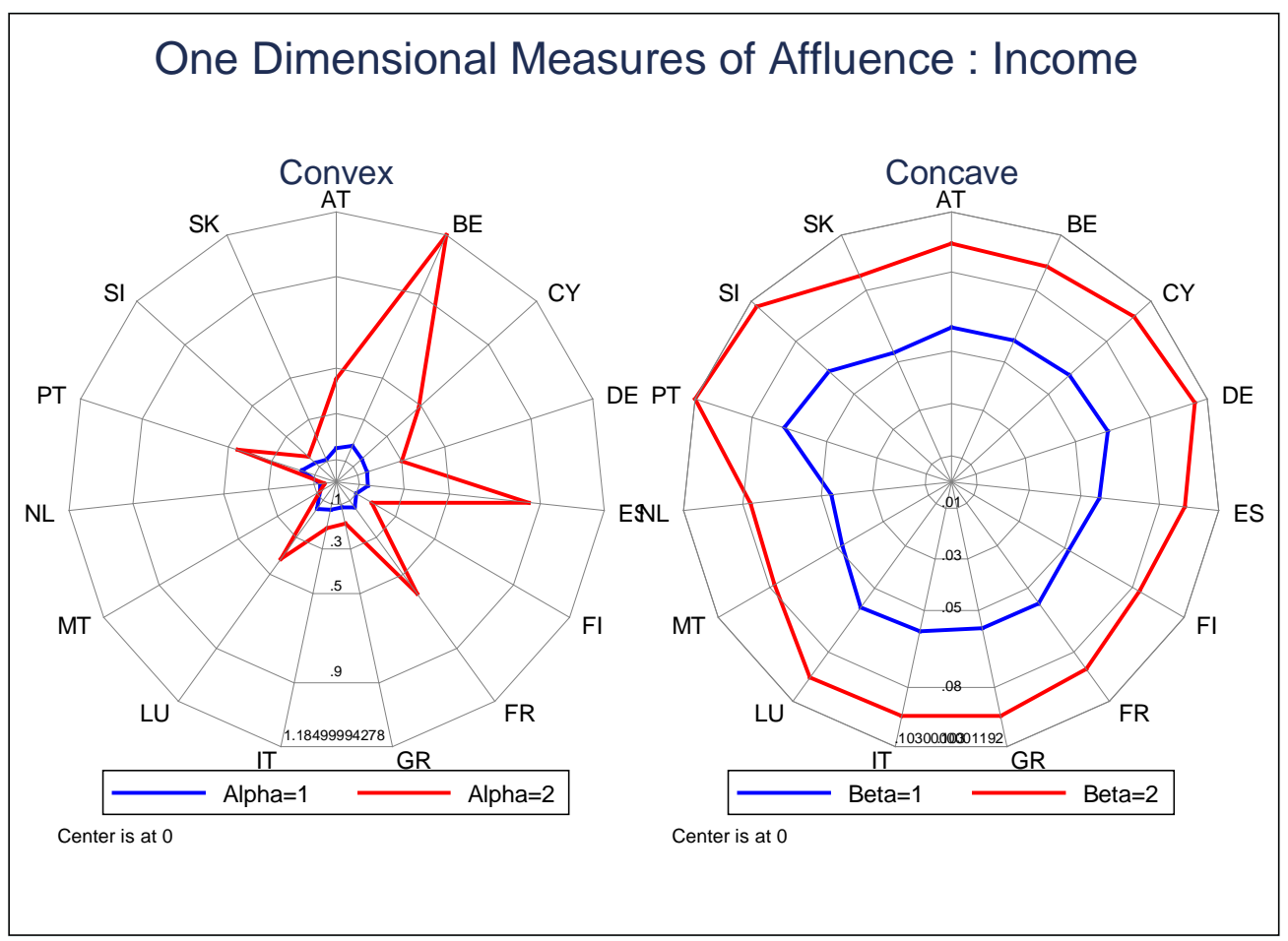

Table 4. One Dimensional Affluence Measures: Income

\begin{tabular}{cccc|ccc}
\hline & $\boldsymbol{R}_{\boldsymbol{\alpha}=\mathbf{1}}^{\boldsymbol{M}}$ & $\boldsymbol{R}_{\boldsymbol{\alpha}=\mathbf{2}}^{\boldsymbol{M}}$ & $\boldsymbol{R}_{\boldsymbol{\alpha}=\mathbf{3}}^{\boldsymbol{M}}$ & $\boldsymbol{R}_{\boldsymbol{\beta}=\mathbf{1}}^{\boldsymbol{M}}$ & $\boldsymbol{R}_{\boldsymbol{\beta}=\mathbf{2}}^{\boldsymbol{M}}$ & $\boldsymbol{R}_{\boldsymbol{\beta}=\mathbf{3}}^{\boldsymbol{M}}$ \\
\hline AT & 0.148 & 0.452 & 3.052 & 0.059 & 0.091 & 0.112 \\
$\mathbf{B E}$ & 0.173 & 1.185 & 28.859 & 0.059 & 0.090 & 0.109 \\
$\mathbf{C Y}$ & 0.150 & 0.487 & 3.529 & 0.061 & 0.094 & 0.115 \\
DE & 0.141 & 0.300 & 1.511 & 0.063 & 0.098 & 0.119 \\
ES & 0.139 & 0.850 & 68.984 & 0.057 & 0.090 & 0.111 \\
FI & 0.101 & 0.179 & 1.046 & 0.052 & 0.083 & 0.104 \\
FR & 0.135 & 0.605 & 14.686 & 0.057 & 0.088 & 0.109 \\
GR & 0.114 & 0.187 & 1.062 & 0.057 & 0.091 & 0.112 \\
IT & 0.122 & 0.205 & 0.617 & 0.058 & 0.091 & 0.111 \\
LU & 0.144 & 0.417 & 2.769 & 0.059 & 0.092 & 0.113 \\
MT & 0.083 & 0.083 & 0.145 & 0.048 & 0.078 & 0.098 \\
NL & 0.074 & 0.054 & 0.060 & 0.046 & 0.077 & 0.098 \\
PT & 0.163 & 0.457 & 3.646 & 0.067 & 0.103 & 0.124 \\
SI & 0.125 & 0.168 & 0.378 & 0.063 & 0.100 & 0.122 \\
SK & 0.108 & 0.222 & 1.352 & 0.054 & 0.086 & 0.107 \\
\hline Sour & & & & &
\end{tabular}

Source: HFCS, authors' own calculations. 
Thus it follows that even though the top of the income distribution is equally populated for all countries, the pairwise comparison of countries' convex and concave measures for $\alpha, \beta>1$ demonstrates that the nature of the income distribution of the rich differs in each country . The higher values of concave affluence in Portugal and Slovenia, for example, indicate that income is more homogenously distributed among the rich in these countries. In Spain, Belgium and in France, however, as is suggested by the convex intensity of richness, the highest incomes are primarily concentrated in the hands of a few.

This can also be deduced from Figure 2; compared to Spain, Belgium and France, a lower proportion of households in Portugal and Slovenia earn the top 1\% of Eurozone income. Even though there are several other countries in the sample for which a higher percentage of households earn the top 1\% of Eurozone income than for Spain, Belgium and France, their convex intensity of richness $\left(R_{\alpha>1}^{M}\right)$, and, in turn, the inequality among the rich, is much lower. In Luxembourg, for example, $7.1 \%$ of households earn the top $1 \%$ of Eurozone income. However, the convex measure of affluence $\left(R_{\alpha>1}^{M}\right)$ in Luxembourg is the lowest among all countries while the concave measure of affluence in Luxembourg is very close to that for Spain, Belgium and France $\left(R_{\beta>1}^{M}\right)$. This result derives from the fact that there are few very rich households in Spain, Belgium and France.

Figure 2. Percentage of Households Earning the Top 1\% of Total Income in the Eurozone ${ }^{24}$

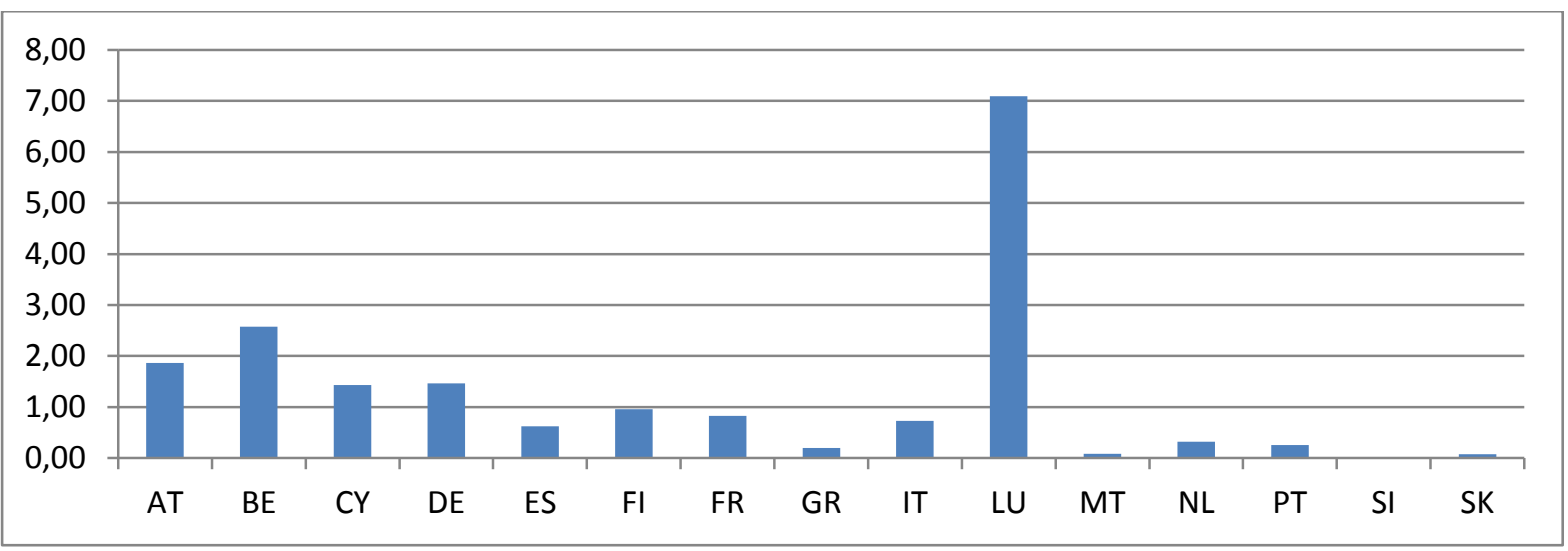

Note: Each bar represents the percentage of households in the corresponding country earning the top $1 \%$ of Total Income. Approximately 7\% of households in Luxembourg are in the top 1\% of Eurozone income distribution.

\footnotetext{
${ }^{24}$ Figure A.1 in the Appendix demonstrates an analogous chart for PPP adjusted income values. The PPP adjusted income is calculated by scaling the net wealth values by the ratio of average income in Austria to the average income of the corresponding country. The share of households earning the top 1\% PPP adjusted income is highest in Belgium (approximately 2\%) and Luxembourg is no longer an outlier with 1\% of households earning the top $1 \%$ total income in the Eurozone.
} 
In addition to the richness measures above, we also present another measure of inequality which is sensitive to the changes at the top of the distribution for all countries. Figure 3 presents the generalized entropy measure (GE) of income for each country where the sensitivity parameter is equal to 2 . We observe that Belgium is the country with the highest GE(2) measure while the Netherlands is the country with the lowest GE(2) index. This confirms our findings relevant to convex affluence measures and thus suggests that the income inequality among the rich in Belgium is higher than in any other country in the sample. Spain, France and Portugal follow Belgium in terms of income inequality.

Figure 3: GE(2) vs. Convex and Concave Affluence Measures for Income

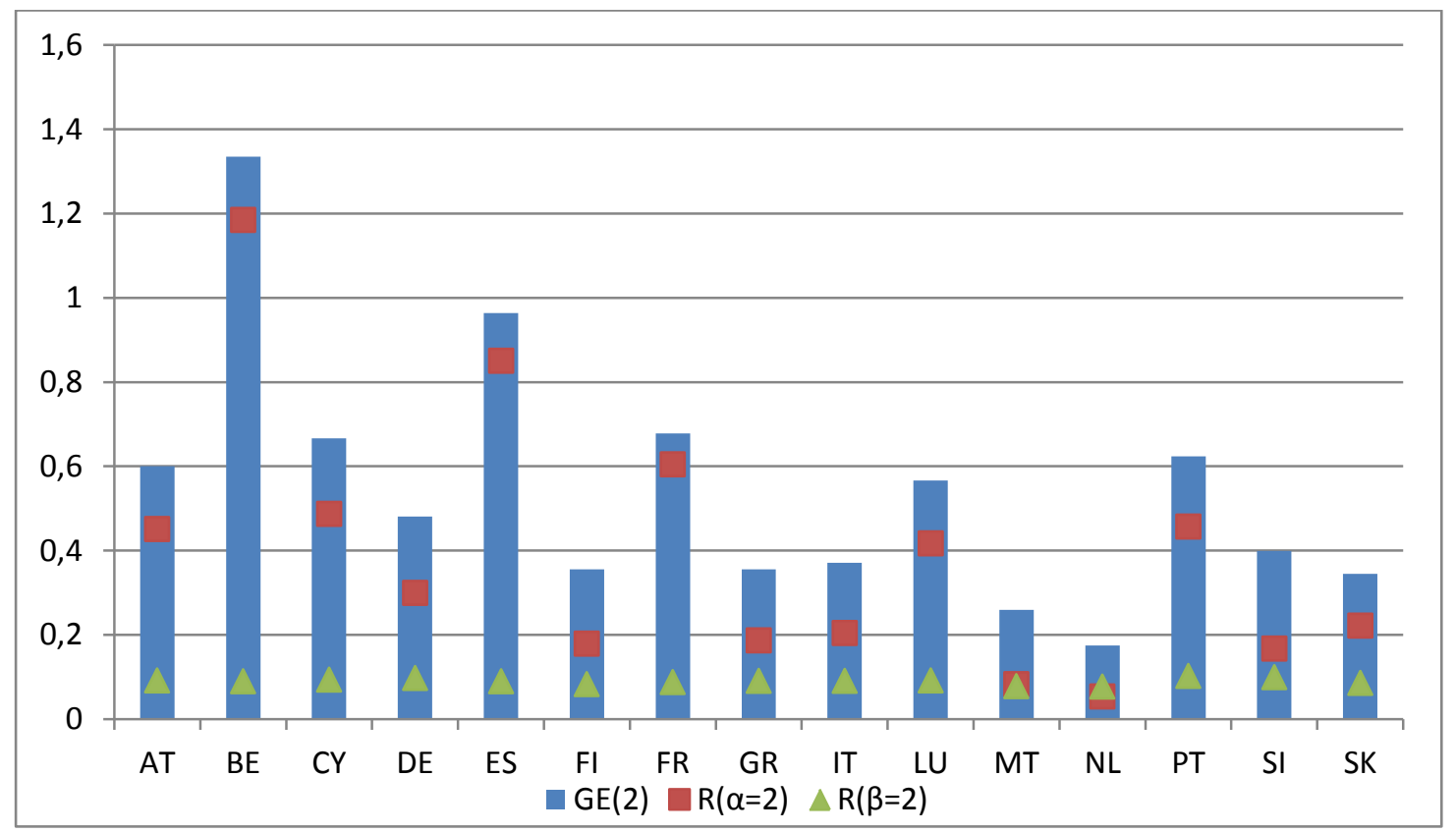

Wealth. Relying on wealth as a measure of affluence (reported in Table 5 and visualized in Figure 4), indicates that where $\alpha=1$, the three countries with the highest average dispersion of wealth from the richness line are Austria (46\%), Cyprus (43\%) and Germany (37\%). For Slovenia and for the Netherlands, the convex measure of affluence is the lowest when $\alpha=1$. This is because the wealth owned by the wealthiest households in Slovenia and in the Netherlands deviates from the cut-off value set for the top $20 \%$ of wealth distribution by an average of approximately $14 \%$. As is the case for income, the most significant jump in the convex measure of wealth affluence is observed in Spain and in France as the sensitivity parameter $\alpha$ increases. 
Table 5. One Dimensional Measures for Wealth

\begin{tabular}{|c|c|c|c|c|c|c|}
\hline & $R_{\alpha=1}^{M}$ & $R_{\alpha=2}^{M}$ & $R_{\alpha=3}^{M}$ & $R_{\beta=1}^{M}$ & $R_{\beta=2}^{M}$ & $R_{\beta=3}^{M}$ \\
\hline AT & 0.456 & 6.786 & 246.177 & 0.089 & 0.124 & 0.142 \\
\hline BE & 0.229 & 0.972 & 7.723 & 0.073 & 0.107 & 0.127 \\
\hline CY & 0.430 & 4.219 & 109.679 & 0.093 & 0.128 & 0.146 \\
\hline DE & 0.371 & 5.959 & 336.693 & 0.083 & 0.119 & 0.138 \\
\hline ES & 0.250 & 9.055 & 6187.384 & 0.075 & 0.111 & 0.131 \\
\hline FI & 0.199 & 1.034 & 23.850 & 0.072 & 0.108 & 0.129 \\
\hline FR & 0.279 & 6.160 & 1026.057 & 0.078 & 0.113 & 0.134 \\
\hline GR & 0.181 & 0.450 & 2.442 & 0.071 & 0.106 & 0.126 \\
\hline IT & 0.251 & 1.626 & 33.688 & 0.076 & 0.111 & 0.131 \\
\hline $\mathbf{L U}$ & 0.334 & 3.857 & 91.595 & 0.077 & 0.111 & 0.131 \\
\hline MT & 0.298 & 7.558 & 465.163 & 0.074 & 0.109 & 0.129 \\
\hline NL & 0.142 & 0.288 & 1.380 & 0.064 & 0.098 & 0.119 \\
\hline PT & 0.351 & 8.957 & 905.224 & 0.080 & 0.114 & 0.133 \\
\hline SI & 0.140 & 0.288 & 0.991 & 0.060 & 0.092 & 0.111 \\
\hline SK & 0.162 & 0.396 & 1.773 & 0.066 & 0.100 & 0.121 \\
\hline
\end{tabular}

Source: HFCS, authors' own calculations

Looking at the concave measure of affluence, the highest (lowest) values of are observed for Cyprus and for Austria (Slovenia) for all levels of sensitivity parameter, $\beta$. As is indicated by the concave affluence measure when $\beta$ is equal to 1 , the excess wealth held by the wealthiest households in Austria and Cyprus, wealth which exceeds the richness line, constitutes on average approximately $9 \%$ of the total wealth of the rich. In Slovenia and in the Netherlands, however, the excess wealth above the richness line constitutes $6 \%$ of wealth holdings. For higher values of $\beta$, the concave measure of dimension adjusted wealth affluence increases for all Eurozone countries. Such increases, however, remain insignificant.

On comparing the convex and concave univariate measures of affluence for wealth we observe differences in countries' rankings. Figure 5 for example, shows that almost $8 \%$ of households in Cyprus have wealth above the top 1\% wealth threshold in the Eurozone. As has already been mentioned, Cyprus has a higher measure of concave affluence compared to the rest of the Eurozone countries. It is, however, Spain that is ranked first with respect to the convex measure of affluence (i.e. $R_{\alpha>1}^{M}$ ). One explanation for this finding could be that in 
Spain, the very high level of wealth is concentrated in the hands of very few, whilst in Cyprus, the distribution of wealth is more homogenous.

Figure 4. Comparison of One Dimensional Measures of Affluence for Wealth

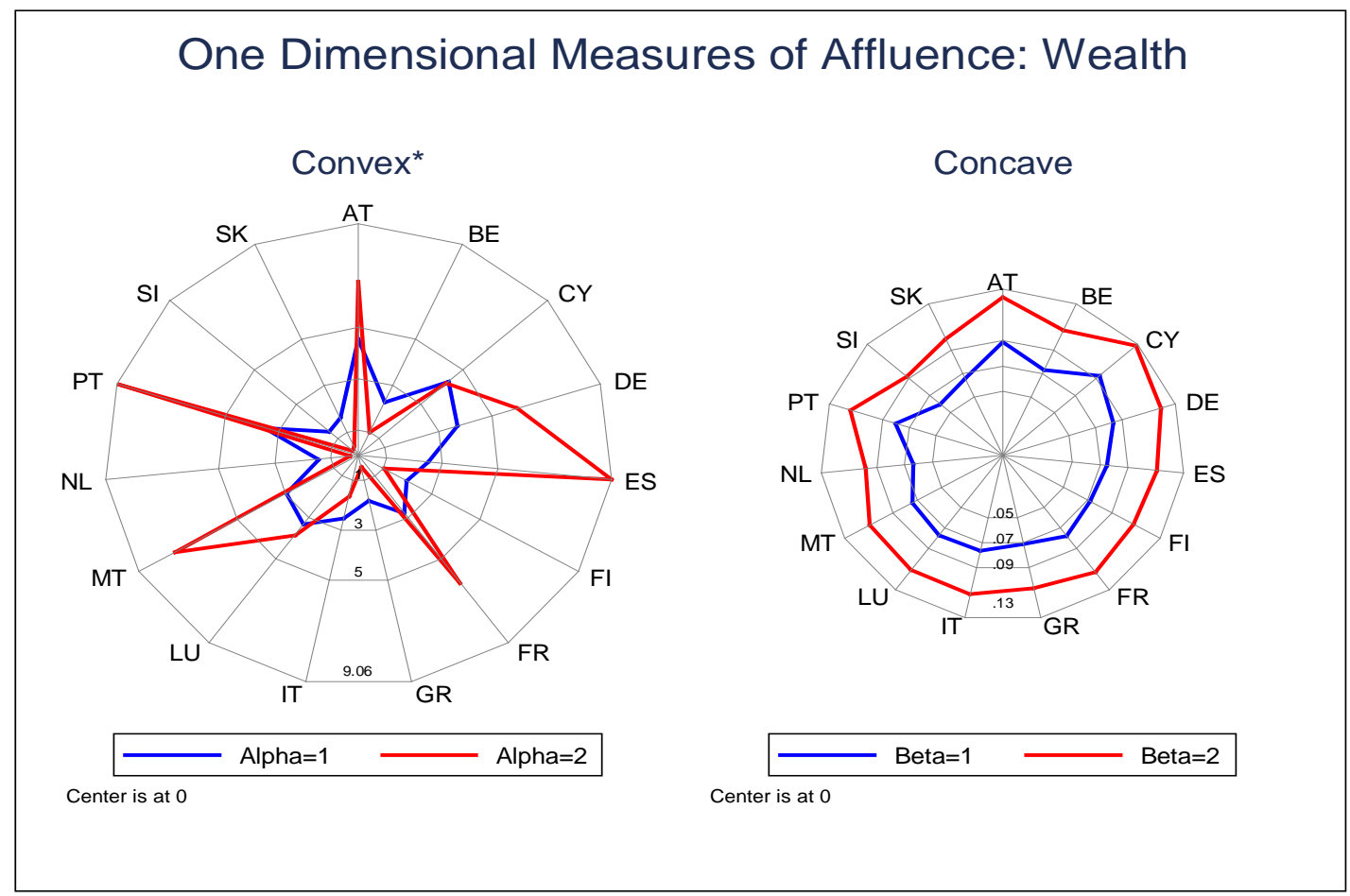

Note: $(*)$ Values of convex affluence measures for $\alpha=1$ are scaled up by a multiple of 10 for visibility.

Figure 5. Percentage of Households in Each Country Holding Top 1\% of Eurozone Wealth ${ }^{25}$

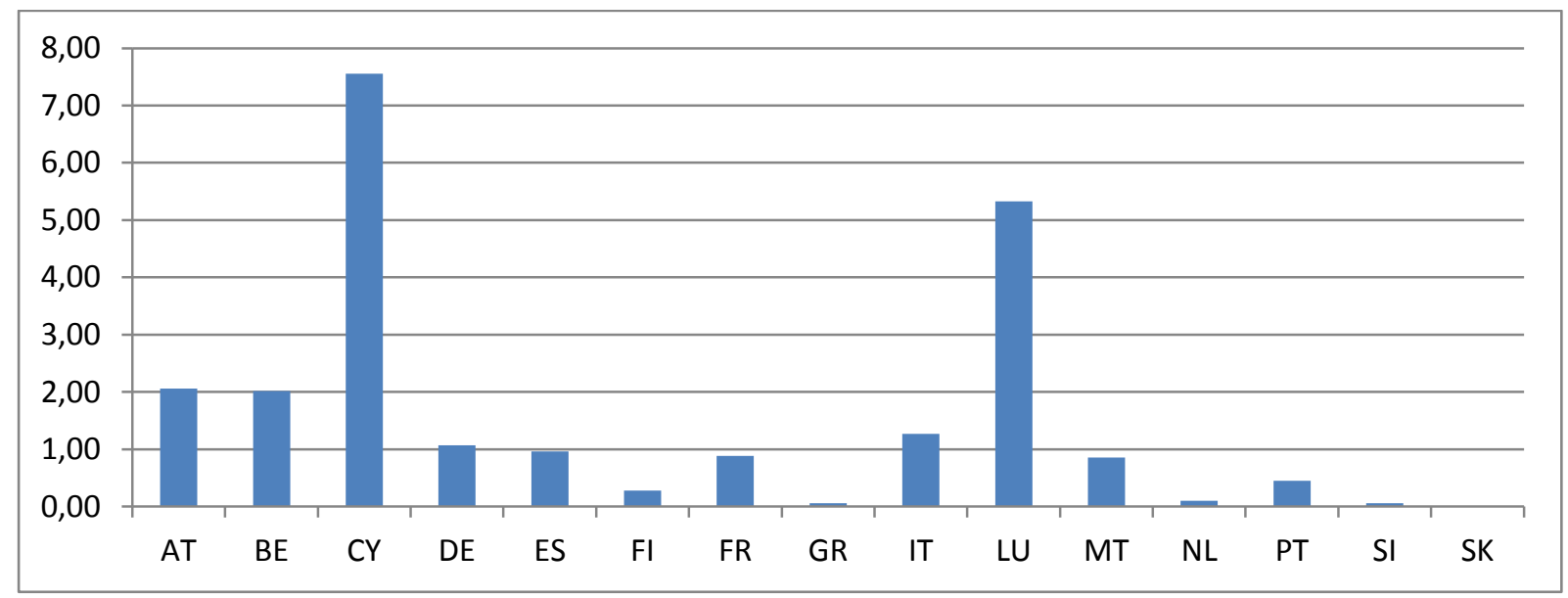

Note: Each bar represents the percentage of households in the corresponding country holding the top $1 \%$ of total net wealth in the Eurozone. For instance, more than 7.5\% of households in Cyprus are in the top 1\% of Eurozone wealth distribution.

${ }^{25}$ Figure A.2 in the Appendix demonstrates an analogous chart for PPP adjusted net wealth values. The PPP adjusted net wealth is calculated by scaling the net wealth values by the ratio of average wealth in Austria to the average wealth of the corresponding country. The share of households earning the top 1\% PPP adjusted wealth is again highest in Cyprus, this share is, however, approximately $2 \%$. 
Figure 6. GE(2) vs. Convex and Concave Affluence Measures for Wealth

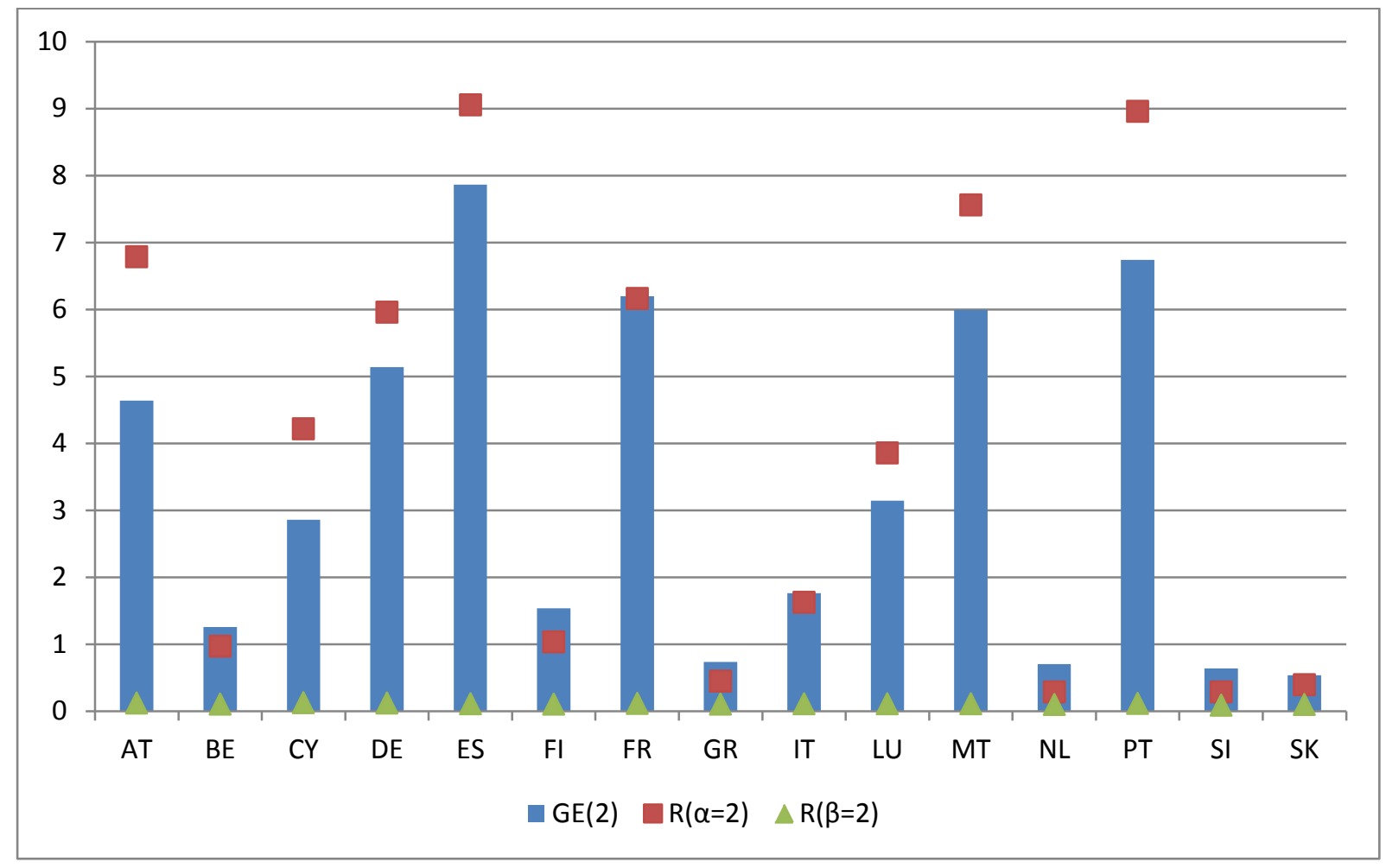

As can be observed from Figure 6, the generalized entropy index for wealth is highest for Spain, followed by Portugal and France. The lowest GE(2) values are measured for Slovakia and Slovenia. These results are also consistent with our observations for $R_{\alpha>1}^{M}$, indicating that the inequality among the top of the net wealth distribution is highest in Spain, while the density of the net wealth distribution among the top is the lowest, yet more equally distributed, for Slovenia and Slovakia.

\subsection{JOINT ANALYSIS OF INCOME AND WEALTH}

\subsubsection{RANK CORRELATIONS:}

Table 6 shows the correlations between income and net wealth. The left-hand block presents the correlation coefficients between dimensions whereas the right-hand block presents the Spearman rank correlations. The first columns of each block display the results when population weights are employed and the second columns display the correlations when the population weights are not implemented in the calculations. 
Table 6. Correlations Between Dimensions

\begin{tabular}{llcc|cc}
\hline & & \multicolumn{2}{c|}{ CORRELATION } & \multicolumn{2}{c}{$\begin{array}{c}\text { SPEARMAN RANK } \\
\text { CORRELATION }\end{array}$} \\
& & (weighted) & (unweighted) & (unweighted) & (weighted) \\
\hline & & Net Wealth & Net Wealth & Net Wealth & Net Wealth \\
AT & Income & 0.241 & 0.240 & 0.486 & 0.487 \\
BE & Income & 0.177 & 0.211 & 0.426 & 0.454 \\
CY & Income & 0.423 & 0.337 & 0.506 & 0.521 \\
DE & Income & 0.361 & 0.462 & 0.561 & 0.597 \\
ES & Income & 0.245 & 0.230 & 0.431 & 0.580 \\
FI & Income & 0.592 & 0.601 & 0.447 & 0.471 \\
FR & Income & 0.441 & 0.517 & 0.533 & 0.613 \\
GR & Income & 0.421 & 0.767 & 0.416 & 0.408 \\
IT & Income & 0.480 & 0.530 & 0.515 & 0.521 \\
LU & Income & 0.473 & 0.445 & 0.538 & 0.563 \\
MT & Income & 0.187 & 0.203 & 0.377 & 0.387 \\
NL & Income & 0.254 & 0.303 & 0.225 & 0.270 \\
PT & Income & 0.477 & 0.480 & 0.402 & 0.420 \\
SI & Income & 0.378 & 0.323 & 0.349 & 0.352 \\
SK & Income & 0.285 & 0.334 & 0.342 & 0.340 \\
\hline Sour & & & &
\end{tabular}

Source: HFCS, authors' calculations

The weighted correlation coefficients are lower than weighted rank correlations for the majority of countries. Exceptions are Finland, Greece, the Netherlands, Portugal and Slovenia. Hence, the correlation between the income and wealth dimensions is weaker than the correlation between the rankings of households in each dimension. Germany exhibits the highest and the Netherlands the lowest rank correlations. Thus, the likelihood of high-income households being ranked as high-wealth owners is considerably higher in Germany than in the other countries in the sample. The association between households' income and wealth rankings is the weakest in the Netherlands. We might recall that the weak correlation between income and net wealth rankings in the Netherlands were also reflected in headcount ratios presented in Table 3.

The differences between countries in regard to the correlation between income and net wealth might be explained by permanent income hypothesis. The basic presumptions of the permanent income hypothesis suggests that for the sake of consumption smoothing over the 
life cycle, individuals, when making decisions regarding consumption, take into account, not only their current income, but also their future expected income, or, in other words, their permanent income. Thus, the differences between households' saving behaviors, which depend on household characteristics such as preferences, household size, age structure etc., could impair the correlation between the income and wealth distributions as well as the correlation between the position of a given household in wealth distribution and in income distribution (i.e. rank correlation).

Piketty (2013) proposes that gifts and inheritances may serve as a source of wealth inequality across generations. Arrondel et.al. (2014) examine the effect of intergenerational transfers on the household position in wealth distribution by using HFCS data. They found that $30 \%$ of households in the Eurozone received gifts or inheritances while this ratio is less than $10 \%$ for the Netherlands, 45\% in Cyprus, and 40\% in Slovenia and in France. These inheritances and gifts are mostly received by households at the top of the wealth distribution. Arrondel et.al. (2014) suspect that gifts and inheritances could explain the discrepancies in correlation between income and wealth distribution. Moreover, the differences across countries with respect to the income and wealth correlations could also be (at least partially) attributed to behavioral and constitutional differences relevant to gifts and inheritances. For instance, the lowest correlation between income and wealth is observed in the Netherlands, yet, at the same time, in comparison with other Eurozone countries, the Netherlands is the country in which the lowest percentage of households receive gifts and inheritances. This suggests that the gifts and inheritances which are given to the $10 \%$ of households in Netherlands is a significant amount and that together with the Netherlands' tax system, which favors wealth, it lowers the correlation between income and net wealth.

\subsubsection{MULTIDIMENSIONAL AFFLUENCE MEASURES}

Table 7 presents the values of multidimensional well-being measures for different cut-off thresholds, $\mathrm{k}$, and for different values of sensitivity parameters, $\alpha$ and $\beta$. The results are also visualized in Figure 7. When the second cut-off is set to $1(k=1)$, i.e. a household is considered as multidimensionally affluent when the household is affluent in at least one dimension, the headcount ratio gives the percentage of households affluent in at least one dimension as presented in Table 3. Where it is necessary to be well-off in both dimensions (i.e. $\mathrm{k}=2$ ) in order to be considered multidimensionally affluent, however, the headcount ratio is identical to the value of the well-off counts in both dimensions, as in Table 3. 
Table 7. Multidimensional Measures of Affluence

\begin{tabular}{|c|c|c|c|c|c|c|c|c|c|c|}
\hline Country & $\begin{array}{l}\text { Second } \\
\text { cut-off }\end{array}$ & $H R(k)$ & $A A S(k)$ & $R_{H R}^{M}(k)$ & $R_{\alpha=1}^{M}$ & $R_{\alpha=2}^{M}$ & $R_{\alpha=3}^{M}$ & $R_{\beta=1}^{M}$ & $R_{\beta=2}^{M}$ & $R_{\beta=3}^{M}$ \\
\hline \multirow{2}{*}{ AT } & $\mathrm{k}=1$ & 0.303 & 0.659 & 0.200 & 0.302 & 3.619 & 124.615 & 0.074 & 0.108 & 0.127 \\
\hline & $k=2$ & 0.097 & 1 & 0.097 & 0.179 & 2.088 & 65.607 & 0.040 & 0.056 & 0.065 \\
\hline \multirow{2}{*}{$\mathbf{B E}$} & $k=1$ & 0.325 & 0.615 & 0.200 & 0.201 & 1.079 & 18.291 & 0.066 & 0.098 & 0.118 \\
\hline & $\mathrm{k}=2$ & 0.075 & 1 & 0.075 & 0.090 & 0.375 & 2.872 & 0.028 & 0.042 & 0.049 \\
\hline \multirow{2}{*}{$\mathbf{C Y}$} & $\mathrm{k}=1$ & 0.299 & 0.666 & 0.199 & 0.290 & 2.353 & 56.604 & 0.077 & 0.111 & 0.131 \\
\hline & $k=2$ & 0.099 & 1 & 0.099 & 0.181 & 1.630 & 31.064 & 0.042 & 0.059 & 0.068 \\
\hline \multirow{2}{*}{ DE } & $\mathrm{k}=1$ & 0.300 & 0.666 & 0.200 & 0.256 & 3.130 & 169.102 & 0.073 & 0.108 & 0.129 \\
\hline & $\mathrm{k}=2$ & 0.100 & 1 & 0.100 & 0.182 & 2.759 & 156.632 & 0.042 & 0.060 & 0.070 \\
\hline \multirow{2}{*}{ ES } & $\mathrm{k}=1$ & 0.304 & 0.653 & 0.198 & 0.194 & 4.953 & 3128.184 & 0.066 & 0.100 & 0.121 \\
\hline & $\mathrm{k}=2$ & 0.093 & 1 & 0.093 & 0.130 & 2.406 & 708.343 & 0.037 & 0.053 & 0.063 \\
\hline \multirow{2}{*}{ FI } & $\mathrm{k}=1$ & 0.310 & 0.645 & 0.200 & 0.150 & 0.607 & 12.448 & 0.062 & 0.095 & 0.116 \\
\hline & $k=2$ & 0.090 & 1 & 0.090 & 0.099 & 0.544 & 12.281 & 0.034 & 0.051 & 0.060 \\
\hline \multirow{2}{*}{ FR } & $k=1$ & 0.296 & 0.676 & 0.200 & 0.207 & 3.383 & 520.372 & 0.067 & 0.101 & 0.121 \\
\hline & $k=2$ & 0.104 & 1 & 0.104 & 0.155 & 3.075 & 488.073 & 0.042 & 0.062 & 0.072 \\
\hline \multirow{2}{*}{ GR } & $\mathrm{k}=1$ & 0.309 & 0.646 & 0.200 & 0.148 & 0.319 & 1.752 & 0.064 & 0.098 & 0.119 \\
\hline & $k=2$ & 0.090 & 1 & 0.090 & 0.081 & 0.206 & 1.408 & 0.033 & 0.049 & 0.058 \\
\hline \multirow{2}{*}{ IT } & $\mathrm{k}=1$ & 0.296 & 0.675 & 0.200 & 0.187 & 0.915 & 17.153 & 0.067 & 0.101 & 0.121 \\
\hline & $\mathrm{k}=2$ & 0.103 & 1 & 0.103 & 0.133 & 0.807 & 16.636 & 0.041 & 0.060 & 0.071 \\
\hline \multirow{2}{*}{$\mathbf{L U}$} & $\mathrm{k}=1$ & 0.302 & 0.661 & 0.200 & 0.239 & 2.137 & 47.182 & 0.068 & 0.101 & 0.122 \\
\hline & $\mathrm{k}=2$ & 0.097 & 1 & 0.097 & 0.163 & 1.875 & 45.125 & 0.038 & 0.055 & 0.065 \\
\hline \multirow{2}{*}{ MT } & $\mathrm{k}=1$ & 0.329 & 0.608 & 0.200 & 0.191 & 3.820 & 232.654 & 0.061 & 0.093 & 0.113 \\
\hline & $\mathrm{k}=2$ & 0.071 & 1 & 0.071 & 0.124 & 3.726 & 232.403 & 0.026 & 0.039 & 0.046 \\
\hline \multirow{2}{*}{ NL } & $\mathrm{k}=1$ & 0.333 & 0.599 & 0.200 & 0.108 & 0.171 & 0.720 & 0.055 & 0.088 & 0.109 \\
\hline & $\mathrm{k}=2$ & 0.066 & 1 & 0.066 & 0.047 & 0.093 & 0.438 & 0.021 & 0.033 & 0.040 \\
\hline \multirow{2}{*}{ PT } & $\mathrm{k}=1$ & 0.304 & 0.658 & 0.200 & 0.257 & 4.707 & 454.435 & 0.073 & 0.108 & 0.128 \\
\hline & $\mathrm{k}=2$ & 0.096 & 1 & 0.096 & 0.179 & 4.349 & 445.192 & 0.042 & 0.059 & 0.068 \\
\hline \multirow{2}{*}{ SI } & $\mathrm{k}=1$ & 0.296 & 0.675 & 0.200 & 0.133 & 0.228 & 0.685 & 0.062 & 0.096 & 0.117 \\
\hline & $\mathrm{k}=2$ & 0.103 & 1 & 0.103 & 0.087 & 0.173 & 0.554 & 0.037 & 0.056 & 0.067 \\
\hline \multirow{2}{*}{ SK } & $\mathrm{k}=1$ & 0.321 & 0.622 & 0.200 & 0.135 & 0.309 & 1.563 & 0.060 & 0.093 & 0.114 \\
\hline & $k=2$ & 0.078 & 1 & 0.078 & 0.067 & 0.163 & 0.735 & 0.027 & 0.041 & 0.049 \\
\hline
\end{tabular}

Source: HFCS, authors' calculations 
As we set the initial cut-off for income and wealth distributions to the top $80 \%$ quantile, the dimension adjusted headcount ratio, $R_{H R}^{M}(k)$, is equal to0.2 for all countries when $k=1$. The multidimensional headcount ratio is much lower for $k=2$ and it represents the total affluence counts. Note that, because the second cut-off threshold is set at a value which is equal to the total number of dimensions (i.e. $k=2$ ), the dimension adjusted headcount ratio is identical to the headcount ratio $\left(R_{H R}^{M}(2)=H R(2)\right)$.

Figure 7. Comparison of Convex Multidimensional Measures for $\mathrm{k}=2$

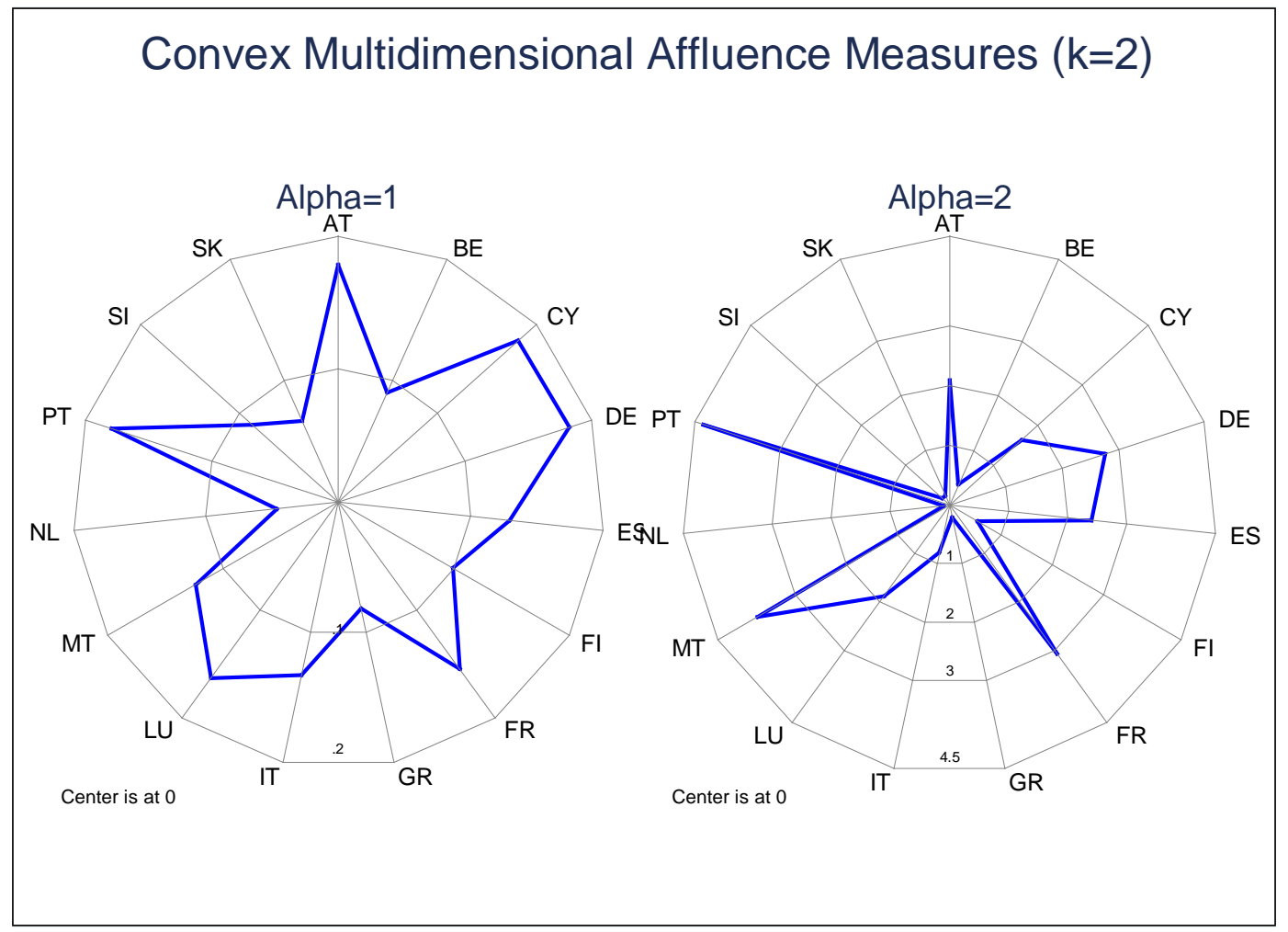

Note: A figure that displays the comparison of convex multidimensional affluence measures when $\mathrm{k}=1$ is included in Appendix A.9.

The convex multidimensional affluence measures indicate that when $\alpha=1$ and households are well-off in both dimensions (i.e. $k=2$ ), Germany, Cyprus, Portugal and Austria have higher affluence measures than the other Eurozone countries in the sample. The dispersion of convex multivariate affluence measures across the Eurozone countries is much greater for higher values of $\alpha$. The largest value for the convex multidimensional affluence measure is observed for Portugal (4.35) when $\alpha=2$. Malta (3.73), France (3.07) and Germany (2.75) follow behind Portugal. 
In regard to the concave multidimensional affluence measures (see Figure 8), France always has the highest value for all levels of the second cut-off threshold. We find that Germany and Italy have the second highest values for the concave measure of richness $\boldsymbol{R}_{\boldsymbol{\beta}=\mathbf{2}}^{\boldsymbol{M}}$ with $6 \%$. Cyprus and Portugal (5.9\%)follow closely behind.

Figure 8. Comparison of Concave Multidimensional Measures for k=2

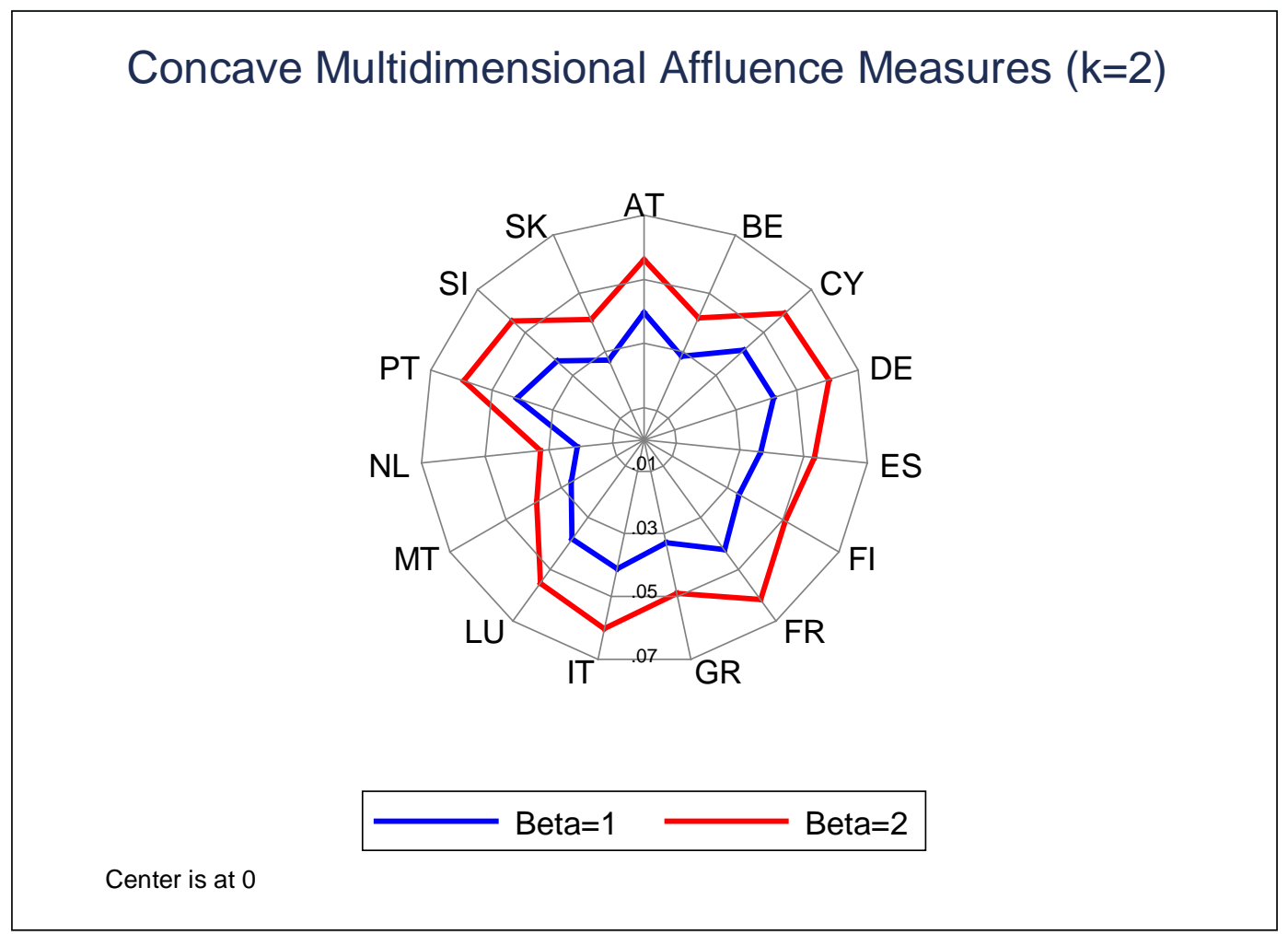

Note: A figure that displays the comparison of concave multidimensional affluence measures when $k=1$ is included in Appendix A.10.

Thus, for $k=2$ and $\alpha, \beta \geq 1$, the pairwise comparison of countries with the highest values of convex and concave affluence measures indicates that France has the highest percentage of households affluent in both dimensions $\left(R_{H R}^{M}(2)=10.4 \%\right)$ and maintains its lead in concave affluence measures (see $R_{\beta \geq 1}^{M}$ ). In terms of the convex measure $R_{\alpha=2}^{M}(2)$, however, Portugal is ranked first. This indicates that in Portugal, richness is predominantly concentrated in the hands of a few, whilst in France, the distribution of richness among affluent households is more homogenous.

A similar conclusion may also be drawn on comparison of Germany and Portugal:; the group of rich households is more populated in Germany and the richness is distributed more evenly among the rich households. Comparison of Germany and Italy indicates an equal concave 
intensity of richness $\left(R_{\beta>1}^{M}\right)$ for both countries, whilst the convex measure of affluence is larger for Germany.

Given that Germany has a slightly more populated group of affluent households, and that the homogeneity of the distribution of richness among the rich households is equal in both countries, the richest of the rich households in Germany are earning more than Italian households.

The analysis of Peichl and Pestel (2013a) provides a basis for further comparison of Germany. Peichl and Pestel (2013a) measured the multidimensional affluence for the rich in Germany and the US for the year 2007. The analysis carried out for Germany is based on the German Socio-Economic Panel Study (SOEP). The comparison of the dimension adjusted headcount ratios for $k=2$ reveals that the percentage of households affluent in both income and wealth is slightly higher in our data (10\% vs. $8.1 \%)$. Our analysis also yields significantly higher values of convex and concave measures of affluence for Germany compared to those reported for the year 2007 in Peichl and Pestel (2013a). While these differences may be partly due to the use of different data sources in two studies, the increases in measures of affluence may also suggest that the economic conditions of the top of the joint distribution in Germany improved during the global financial crisis.

\subsubsection{CONTRIBUTIONS TO MULTIDIMENSIONAL AFFLUENCE:}

This section displays the contribution of income and wealth dimensions to the affluence measures for each country. The percentage contribution of dimensions to the convex affluence measure is demonstrated by Figure 9, whilst Figure 10 displays the contribution of income and wealth dimensions to the concave affluence measure. It can be seen that countries differ substantially in regard to the affluence contribution of each dimension.

For the convex affluence measure, when $\alpha=1$, wealth is a relatively more important dimension than income. This is the case for all countries except Slovenia. With the exception of Germany, Luxemburg, Malta, the Netherlands and Slovakia, the relative importance of wealth declines, or remains at least constant, when the second stage cut-off increases from 1 to 2 . The relative importance of wealth increases in these countries when the second stage cut-off is set at its maximum $(k=2)$. For $\alpha=2$, wealth is a relatively more important dimension than income. Whilst the relative importance of wealth decreases for Cyprus, Finland, Greece, Spain, and Slovenia when the second stage cut-off is increased from 1 to 2, these circumstances result in an increase in the relative importance of wealth for Belgium, Luxemburg, the Netherlands and Slovakia . 
Figure 9. Percentage Dimension Contribution to Convex Affluence Measure:
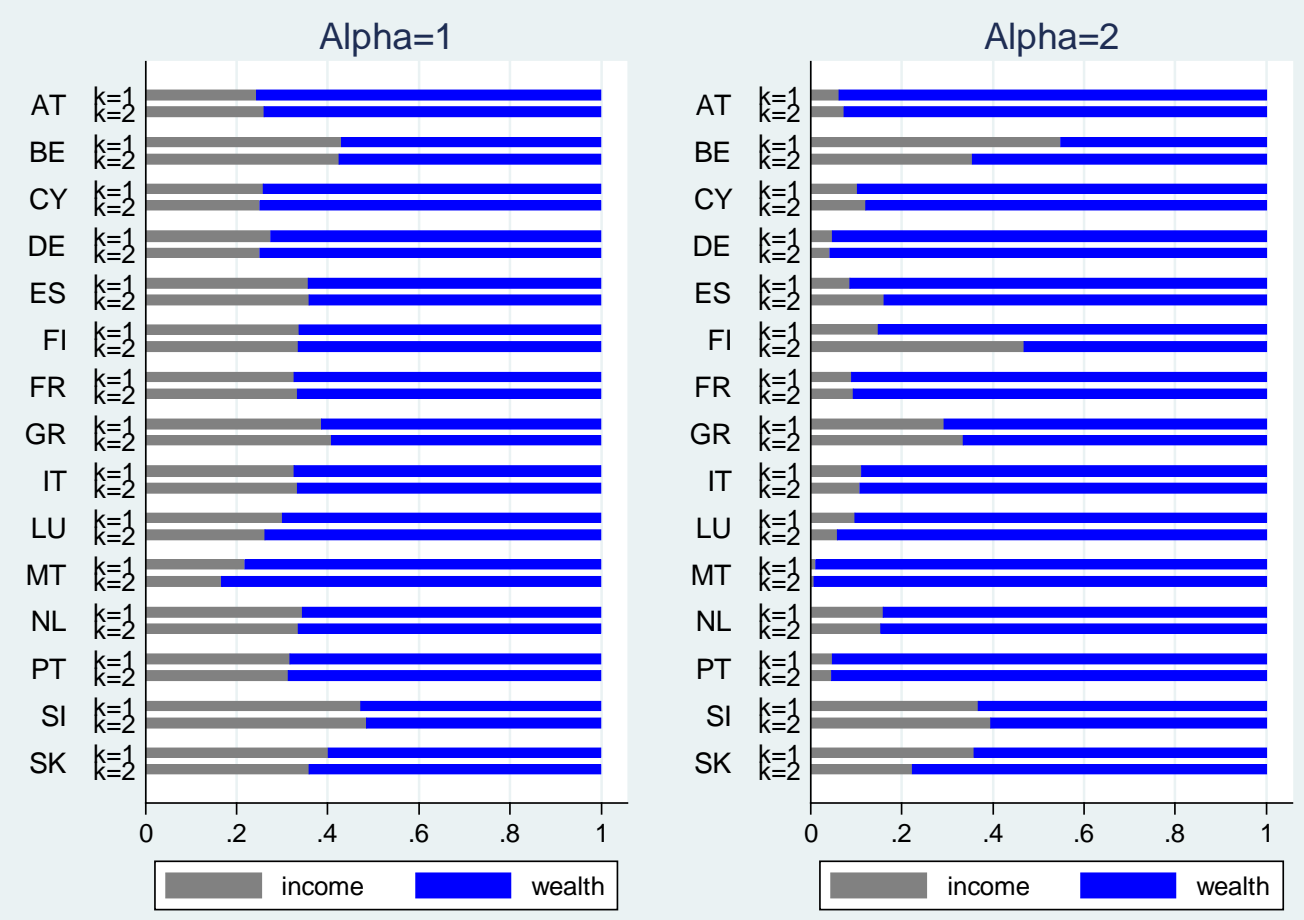

Source: HFCS, authors' own calculations

Figure 10. Percentage Dimension Contribution to Concave Affluence Measure:

Beta $=1$

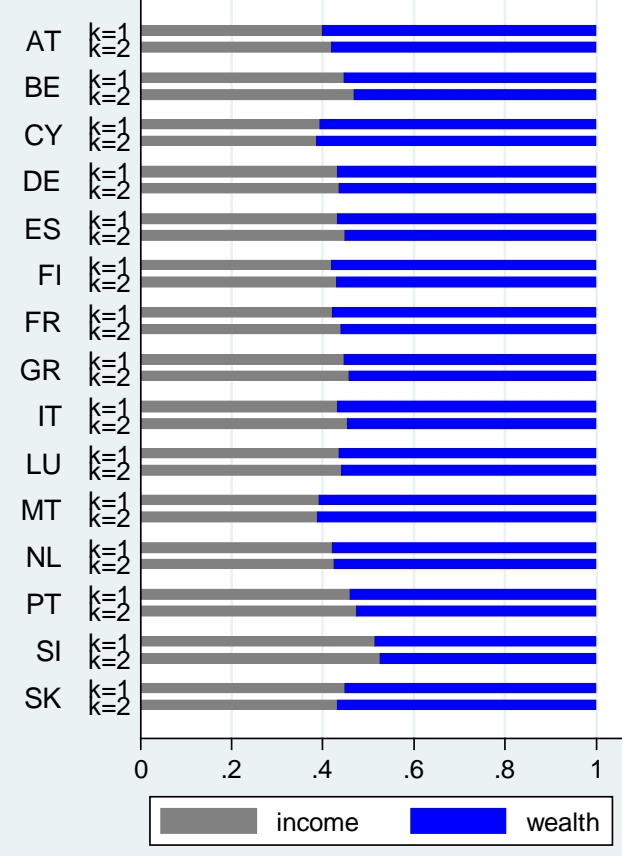

Beta $=2$

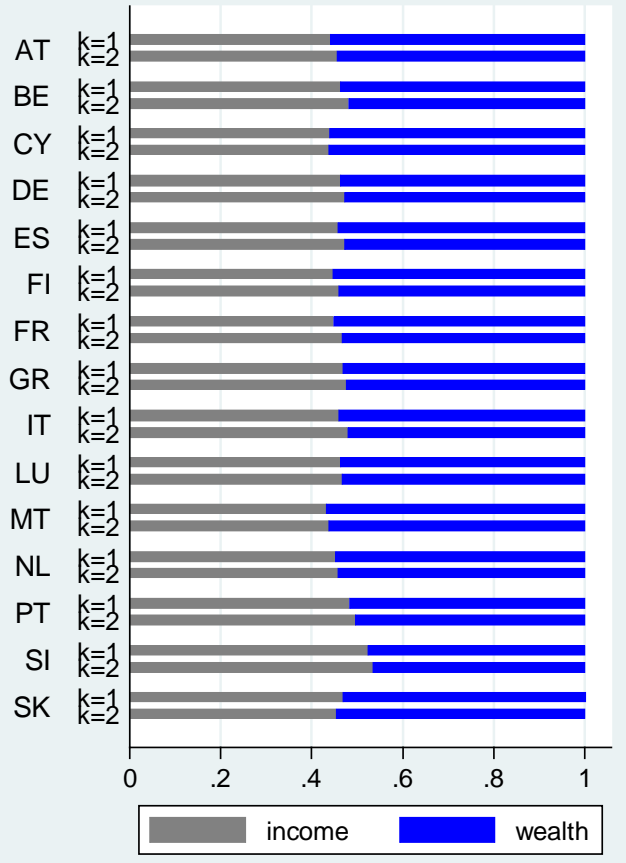

Source: HFCS, authors’ own calculations 
For the concave measure, the relative importance of wealth and income is almost equal for all countries. With the exception of Slovakia, , the relative importance of wealth reduces for both values of the sensitivity parameter $\beta$ when the affluence threshold is raised to 2 .

\section{ROBUSTNESS CHECK}

The results presented in this paper measure affluence for the top $80 \%$ of the income and wealth distribution in 15 Eurozone countries. In order to assess both the multidimensional and unidimensional well-being of the very rich, we have also calculated the affluence measures for the top $90 \%$ and top $99 \%$ quantiles of the income and wealth distribution. Table A.2 in the Appendix shows that the income cut-off values for the top 90\% (99\%) quantile ranges from 156,300 $(385,200)$ Euros in Luxembourg to 24,500 $(47,735)$ Euros in Slovakia while the wealth cut-off values range from 1,524,441 (7,491,000) Euros in Cyprus to 152,800 $(454,084)$ Euros in Slovakia. Table A.2 also presents the cut-off values for purchasing power parity adjusted income and the net wealth for the top $80 \%$ quantile. ${ }^{26}$ The PPP adjusted income values indicate that the income cut-off values range from 67,411 Euros in Slovenia to 59,274 Euros in France. The PPP adjusted net wealth cut-offs range between 461,631 Euros in the Netherlands to 323,169 in Austria.

The one-dimensional affluence measures for the top 90\% and top 99\% quantiles indicate that the rankings of the countries are very similar to the top $80 \%$ quintile as indicated by tables A.3 through A.6 in the Appendix. Multidimensional affluence measures are presented in tables A.7 and A.8 for the top 90\% and 99\% quantiles. Looking at the households which are well-off in both dimensions (i.e. $k=2$ ), there are very few changes in the rankings of the countries in terms of the joint distribution of income and wealth for the top $90 \%$ quintile compared to the top $80 \%$. For the top $99 \%$ quantile of the joint distribution of income and wealth the story is, however, quite different; the highest convex affluence measure is observed for France for all levels of $\alpha$ and we observe that Greece and Slovakia have the highest concave measures of affluence when $\beta=2$.

\section{CONCLUSIONS}

Using the recently published first wave of the HFCS, this paper examines the joint distribution of income and net wealth at the top of the distribution in 15 Eurozone countries.

\footnotetext{
${ }^{26}$ The purchasing power parity is calculated by scaling the income (net wealth) values by the ratio of average income (net wealth) in Austria to the average income (net wealth) of the corresponding country.
} 
The HFCS is a comprehensive survey data which provides valuable information for crosscountry comparison of the wealth distribution in the Eurozone. HFCS is not, however, free from comparability problems and the reader should therefore bear these comparability issues in mind when reading our analysis.

We employ convex and concave measures of affluence proposed by Peichl and Pestel (2013a) in order to measure inequality among the rich. We begin our analysis using one- dimensional measures of affluence by considering income and wealth distributions separately before we examine the joint distribution of income and wealth. The ranking of countries according to the income distribution among the rich indicates that, with respect to the convex affluence measures, Spain and France are more affluent than the other countries in the sample. In regard to the concave affluence measures, however, Portugal and Slovenia are the two most affluent countries. Independent of the measure of affluence, the Netherlands is the least affluent country in the sample. Where the distribution of net wealth constitutes the dimension of affluence, the ranking of countries also depends on the choice of affluence measures. Spain is ranked as the most affluent country according to the convex measure while Cyprus has the highest concave affluence measure in the sample. We can therefore conclude that households' rankings within marginal distributions of income and net wealth are not perfectly correlated. This is further confirmed by correlation coefficients.

In order to further investigate the distribution of affluence, we consider the joint distribution of income and net wealth. The pairwise comparison of countries' multidimensional affluence measures indicates that France has the highest concave affluence measure in the sample. This suggests that, in comparison to other countries in the sample, France has a more homogenous distribution of richness among affluent households. Where the convex measure is $\alpha=2$, Portugal ranks first and where the convex measure is increased, so that $\alpha=3$, it ranks among the top three countries. This indicates that, in Portugal, richness is predominantly concentrated in the hands of a few. Comparison of Germany and Portugal, produces a similar result; the group of rich households is more populated in Germany and the richness is distributed more evenly among the rich households.

Finally, comparing the contribution of each dimension to multidimensional well-being, we find that net wealth is a relatively more important dimension for the convex affluence measure. This is the case for all countries except Slovenia. In regard to the concave affluence 
measure, the contribution of net wealth and income to multidimensional well-being is almost equal for all countries.

Our cross-country comparison of various richness measures indicates wide heterogeneity between countries. The purpose of our analysis is mainly descriptive, and thus, finding causal explanations for these differences is beyond the scope of this paper. Differences in household composition, institutional structures or behavioral attributes across countries could explain theses differences. As noted by Arrondel et. al. (2014), for example, it is not only income, but also intergenerational transfers such as gifts and inheritances, which seem to play a significant role in producing differences in wealth distribution between countries. Arrondel et. al (2014) found that for France, Finland, Germany, Italy and Spain the effect of income on the probability of being in a given wealth decile is heterogeneous while for Germany, Greece, Italy, Slovakia and Spain the impact of intergenerational transfers on wealth accumulation varies. For other countries, the probability of being in higher wealth deciles increases as income and/or intergenerational transfers increase. Redistributive policies, such as income and wealth tax regulations, also vary between countries and are expected to account for differences in measuring richness. Brauninger (2012) summarizes income and wealth tax policies across the euro area; countries such as Spain, Germany and Italy terminated or interrupted the general wealth taxes before the crisis and only Spain restored general wealth taxes in 2011. Among the special wealth taxes, real estate taxes play a significant role in France whilst, in comparison to other countries, capital transfer taxes are more sound in Italy and Spain. Income taxes also vary across countries; in the wake of the crisis the top income taxes are showing an increasing trend. Considering that the share of wealth is greater than, if not equal to, the share of income in affluence measures (with the exception of Slovakia), a tax levied on wealth holdings is expected to have a greater impact on the affluence of households' at the top than an income tax. Household structures such as age, education and size are also expected have an impact on household income and wealth distribution and hence, on richness measures between countries. The saving behavior of households also depends on the age structure such that younger households are expected to hold higher debt (ie. mortgage debt) which reduces their net wealth. Home ownership ratios, values, prices of wealth items and many other structural and behavioral differences between countries are expected to play a role in the variation of affluence at the top of the distribution between countries. Explaining the crosscountry differences in (multidimensional) affluence provides a promising avenue for future research. 


\section{APPENDIX}

A.1. HFCS Data Comparability Across Countries:

Table A.1.1: Reference and Fieldwork Periods for Wealth and Income

\begin{tabular}{llll}
\hline Country & Net Wealth & Income & Fieldwork period \\
\hline Belgium & Time of interview & 2009 & $04 / 10-10 / 10$ \\
Germany & Time of interview & 2009 & $09 / 10-07 / 11$ \\
Greece & Time of interview & Last 12 months & $6 / 09-9 / 09$ \\
Spain & Time of interview & 2007 & $11 / 08-07 / 09$ \\
France & Time of interview & 2009 & $10 / 09-02 / 10$ \\
Italy & 31.12 .2010 & 2010 & $01 / 11-08 / 11$ \\
Cyprus & Time of interview & 2009 & $04 / 10-01 / 11$ \\
Luxembourg & Time of interview & 2009 & $09 / 10-04 / 11$ \\
Malta & Time of interview & Last 12 months & $10 / 10-02 / 11$ \\
Netherlands & 31.12 .2009 & 2009 & $04 / 10-12 / 10$ \\
Austria & Time of interview & 2009 & $09 / 10-05 / 11$ \\
Portugal & Time of interview & 2009 & $04 / 10-07 / 10$ \\
Slovenia & Time of interview & 2009 & $10 / 10-12 / 10$ \\
Slovakia & Time of interview & Last 12 months & $09 / 10-10 / 10$ \\
Finland & 31.12 .2009 & 2009 & $01 / 10-05 / 10$ \\
\hline Soure: & SwF & &
\end{tabular}

Source: HFCS Country Surveys Metadata Information Wave I, Doc.UDB5, ECB, 2013

Figure A.1.1: Response Rates

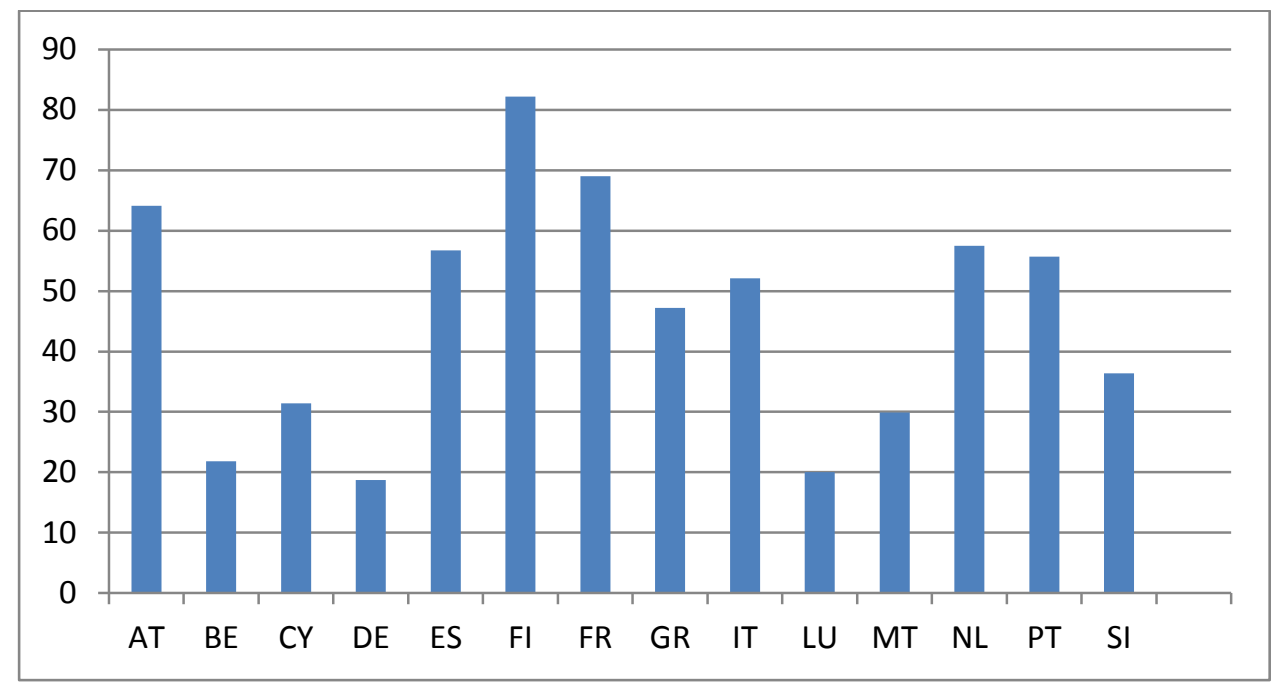

Source: HFCS Country Surveys Metadata Information Wave I, Doc.UDB5, ECB, 2013 
Table A1.2: Number of Covariates used for Main Variables

\begin{tabular}{|c|c|c|c|c|}
\hline Country & $\begin{array}{c}\text { Value of } \\
\text { Household } \\
\text { Main } \\
\text { Residence }\end{array}$ & $\begin{array}{c}\text { Outstanding } \\
\text { Amount of Most } \\
\text { Important HMR } \\
\text { Loan }\end{array}$ & $\begin{array}{l}\text { Value of } \\
\text { Savings } \\
\text { Accounts }\end{array}$ & $\begin{array}{c}\text { Employee } \\
\text { Income }\end{array}$ \\
\hline $\mathrm{AT}$ & 104 & 51 & 133 & 102 \\
\hline $\mathrm{BE}$ & 46 & 31 & 49 & 50 \\
\hline CY & 50 & 38 & 48 & 98 \\
\hline $\mathrm{DE}$ & 84 & 10 & 17 & 20 \\
\hline $\mathrm{ES}$ & 239 & 104 & 159 & 224 \\
\hline FI & n.a & n.a & n.a & n.a \\
\hline FR & 17 & 12 & 21 & 7 \\
\hline GR & 233 & 154 & 49 & 196 \\
\hline $\mathrm{IT}$ & n.a & n.a & 10 & n.a \\
\hline LU & 86 & 118 & 31 & 40 \\
\hline $\mathrm{MT}$ & 4 & 10 & 14 & 8 \\
\hline NL & 6 & 7 & 7 & 5 \\
\hline $\mathrm{PT}$ & 16 & 23 & 17 & 6 \\
\hline SI & 47 & 4 & 14 & 130 \\
\hline SK & 102 & 31 & 69 & 100 \\
\hline
\end{tabular}

Source: HFCS Country Surveys Metadata Information Wave I, Doc.UDB5, ECB, 2013 
Table A.1.3: Impact of Imputation on Aggregate Variables

\begin{tabular}{cccc}
\hline Country & $\begin{array}{c}\text { Gross Real } \\
\text { Wealth }\end{array}$ & $\begin{array}{c}\text { Gross Financial } \\
\text { Wealth }\end{array}$ & $\begin{array}{c}\text { Gross } \\
\text { Income }\end{array}$ \\
\hline AT & 28.6 & 29.8 & 20.0 \\
BE & 5.5 & 31.2 & 12.7 \\
CY & 24.5 & 28.3 & 12.6 \\
DE & 6.6 & 16.8 & 11.7 \\
ES & 6.2 & 10.9 & 3.6 \\
FI & 0.0 & 0.0 & 0.0 \\
FR & 13.5 & 4.7 & 0.0 \\
GR & 4.8 & 25.1 & 6.6 \\
IT & 0.2 & 4.5 & 0.0 \\
LU & 5.5 & 16.7 & 8.8 \\
MT & 10.5 & 24.4 & 6.2 \\
NL & 11.1 & 43.4 & 19.9 \\
PT & 8.0 & 20.5 & 7.3 \\
SI & 16.2 & 18.2 & 12.9 \\
SK & 5.3 & 20.9 & 6.8 \\
\hline Soure: & $55 y s$ & &
\end{tabular}

Source: Eurosystem Household Finance and Consumption Network (2013a)

The values in this table show the weighted sum of all components of the aggregate that were imputed divided by the weighted sum of the aggregate variable. 
Table A.1.4: Oversampling of Wealthy Households

\begin{tabular}{|c|c|c|c|}
\hline Country & Oversampling & $\begin{array}{c}\text { Basis for } \\
\text { Oversampling }\end{array}$ & $\begin{array}{c}\text { Effective } \\
\text { Oversampling } \\
\text { Rate of the Top } \\
10 \%(*)\end{array}$ \\
\hline AT & No & $\begin{array}{l}\text { Regional; real estate } \\
\text { prices }\end{array}$ & 1 \\
\hline $\mathrm{BE}$ & yes & $\begin{array}{l}\text { Average Regional } \\
\text { Income }\end{array}$ & 47 \\
\hline CY & yes & Electricity Consumption & 81 \\
\hline $\mathrm{DE}$ & yes & $\begin{array}{l}\text { Taxable income of } \\
\text { regions }\end{array}$ & 117 \\
\hline ES & yes & $\begin{array}{l}\text { Taxable wealth of } \\
\text { individuals }\end{array}$ & 192 \\
\hline FI & yes & $\begin{array}{l}\text { Individual income and } \\
\text { socio economic status } \\
\text { from populaton register }\end{array}$ & 68 \\
\hline FR & yes & Wealth & 129 \\
\hline GR & yes & $\begin{array}{l}\text { Regional; real estate } \\
\text { prices }\end{array}$ & -2 \\
\hline IT & no & - & 4 \\
\hline LU & yes & $\begin{array}{l}\text { Personal Income subject } \\
\text { to social contributions }\end{array}$ & 55 \\
\hline MT & no & - & -5 \\
\hline NL & no & - & 87 \\
\hline PT & yes & $\begin{array}{l}\text { Regional; real estate } \\
\text { prices }\end{array}$ & 16 \\
\hline SI & no & $\begin{array}{l}\text { Regional; real estate } \\
\text { prices }\end{array}$ & 22 \\
\hline SK & no & - & -11 \\
\hline
\end{tabular}

Source: HFCS Country Surveys Metadata Information Wave I, Doc.UDB5, ECB, 2013

(*) From Eurosystem Household Finance and Consumption Network (2013c, p.10):

Oversampling rate of wealth households: If the share of rich households in the net sample is exactly $10 \%$, then the effective oversampling rate of the top $10 \%$ is 0 . If the share of households in the wealthiest decile is $20 \%$, then the effective oversampling rate is 100 . This meansthat there are $100 \%$ more wealthy households in the sample than there would be if all households were equally weighted. A negative oversampling rate indicates that there are fewer wealthy households in the net sample than there would be if all households were equally weighted. 
Table A.2: Cut-offs

\begin{tabular}{|c|c|c|c|c|}
\hline Country & Dimension & $\begin{array}{c}\text { Cut-off(*) } \\
\text { (PPP adjusted) }\end{array}$ & $\begin{array}{c}\text { Cut-off } \\
\text { (top 99\% quantile) }\end{array}$ & $\begin{array}{c}\text { Cut-off } \\
\text { (top } 90 \% \text { quantile) }\end{array}$ \\
\hline \multirow{2}{*}{ AT } & Income & 60,221 & 232,923 & 79,961 \\
\hline & Net Wealth & 311,200 & $3,029,026$ & 544,862 \\
\hline \multirow{2}{*}{ BE } & Income & 61,190 & 309,300 & 89,600 \\
\hline & Net Wealth & 378,530 & $2,886,320$ & 705,000 \\
\hline \multirow{2}{*}{$\mathbf{C Y}$} & Income & 61,260 & 202,382 & 83,800 \\
\hline & Net Wealth & 304,571 & $7,491,000$ & $1,465,004$ \\
\hline \multirow{2}{*}{ DE } & Income & 61,558 & 198,200 & 85,270 \\
\hline & Net Wealth & 354,427 & $1,930,320$ & 442,000 \\
\hline \multirow{2}{*}{ ES } & Income & 60,294 & 130,777 & 58,060 \\
\hline & Net Wealth & 352,434 & $1,858,996$ & 609,713 \\
\hline \multirow{2}{*}{ FI } & Income & 63,444 & 169,715 & 84,117 \\
\hline & Net Wealth & 431,369 & $1,090,487$ & 397,318 \\
\hline \multirow{2}{*}{ FR } & Income & 58,497 & 161,112 & 64,304 \\
\hline & Net Wealth & 373,345 & $1,778,153$ & 511,417 \\
\hline \multirow{2}{*}{ GR } & Income & 62,976 & 111,000 & 53,326 \\
\hline & Net Wealth & 394,617 & 919,000 & 332,700 \\
\hline \multirow{2}{*}{ IT } & Income & 61,823 & 156,124 & 64,937 \\
\hline & Net Wealth & 361,620 & $2,138,987$ & 577,133 \\
\hline \multirow{2}{*}{$\mathbf{L U}$} & Income & 60,335 & 384,200 & 154,300 \\
\hline & Net Wealth & 331,112 & $6,313,586$ & $1,358,570$ \\
\hline \multirow{2}{*}{ MT } & Income & 65,377 & 87,224 & 51,000 \\
\hline & Net Wealth & 329,704 & $1,868,125$ & 701,643 \\
\hline \multirow{2}{*}{ NL } & Income & 61,729 & 131,617 & 81,867 \\
\hline & Net Wealth & 475,011 & $1,048,550$ & 428,002 \\
\hline \multirow{2}{*}{ PT } & Income & 60,572 & 100,300 & 39,750 \\
\hline & Net Wealth & 326,673 & $1,249,319$ & 297,348 \\
\hline \multirow{2}{*}{ SI } & Income & 66,679 & 93,572 & 50,000 \\
\hline & Net Wealth & 423,201 & 875,400 & 313,325 \\
\hline \multirow{2}{*}{ SK } & Income & 59,942 & 47,264 & 24,320 \\
\hline & Net Wealth & 358,242 & 453,792 & 152,122 \\
\hline
\end{tabular}

Source: HFCS, authors' calculations

$\left({ }^{*}\right)$ The purchasing power parity adjusted cut-off values of income (net wealth) are calculated by scaling the income (net wealth) values by the ratio of average income (net wealth) in Austria to the average income (net wealth) of the corresponding country. 
Figure A.2: Percentage of Households Earning the Top 1\% of Total Income in the Eurozone (PPP adjusted)

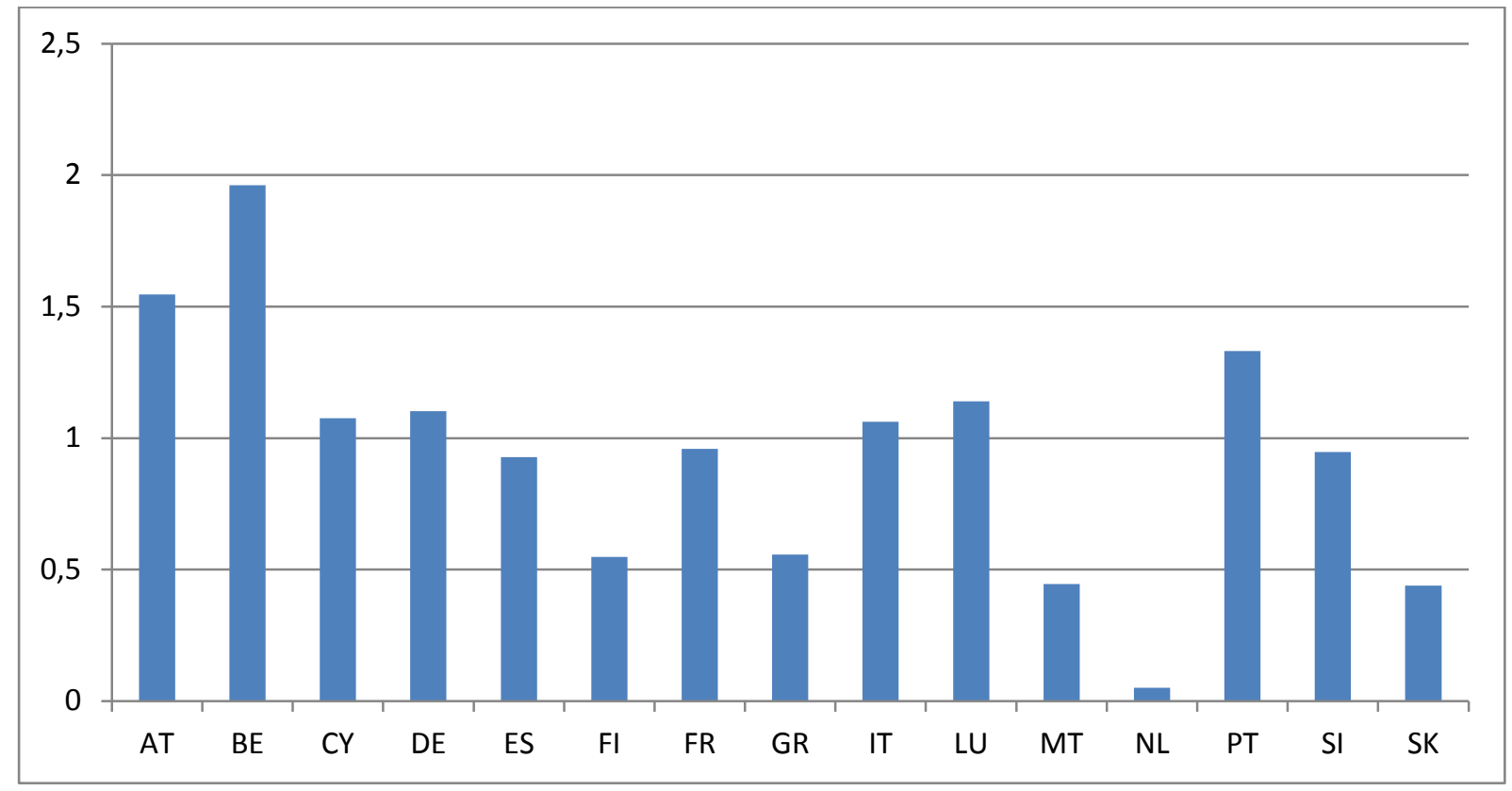

$\left(^{*}\right)$ The purchasing power parity adjusted values of income are calculated by scaling the income values by the ratio of average income in Austria to the average income of the corresponding country.

Figure A.3: Percentage of Households in each Country Holding Top 1\% of Eurozone Wealth (PPP adjusted)

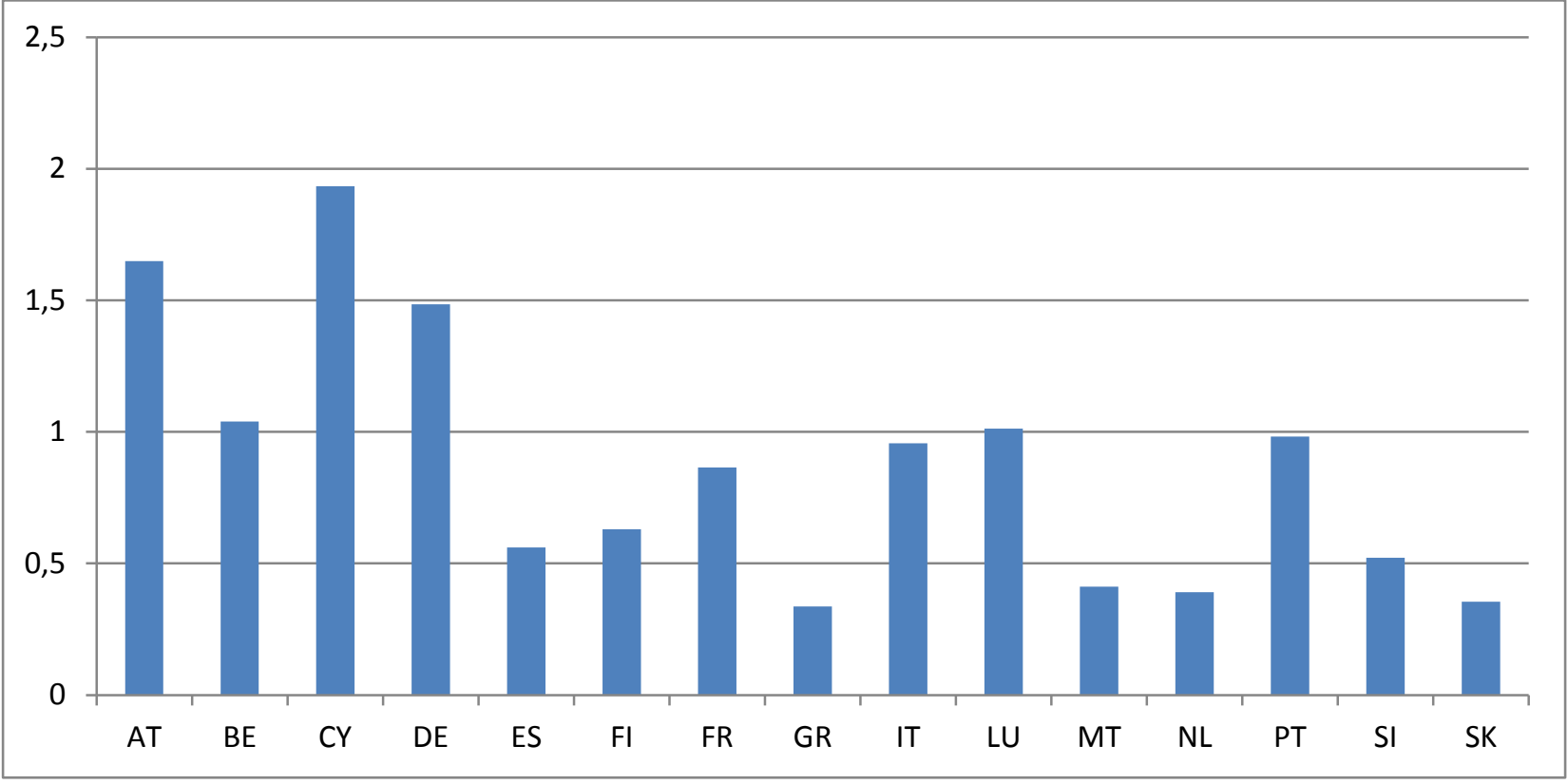

$\left(^{*}\right)$ The purchasing power parity adjusted cut-off values of net wealth are calculated by scaling the net wealth values by the ratio of average net wealth in Austria to the average net wealth of the corresponding country. 
Table A.3: One Dimensional Affluence Measures for Top 90\%:

Income

\begin{tabular}{ccccccc}
\hline & $\boldsymbol{R}_{\boldsymbol{\alpha}=\mathbf{1}}^{M}$ & $\boldsymbol{R}_{\boldsymbol{\alpha}=\mathbf{1}}^{M}$ & $\boldsymbol{R}_{\boldsymbol{\alpha}=\mathbf{1}}^{M}$ & $\boldsymbol{R}_{\boldsymbol{\beta}=\mathbf{1}}^{M}$ & $\boldsymbol{R}_{\boldsymbol{\beta}=\mathbf{1}}^{M}$ & $\boldsymbol{R}_{\boldsymbol{\beta}=\mathbf{1}}^{M}$ \\
\hline AT & 0.076 & 0.211 & 1.132 & 0.030 & 0.045 & 0.055 \\
BE & 0.100 & 0.650 & 12.714 & 0.032 & 0.047 & 0.056 \\
CY & 0.068 & 0.204 & 1.126 & 0.027 & 0.042 & 0.051 \\
DE & 0.060 & 0.109 & 0.443 & 0.029 & 0.045 & 0.056 \\
ES & 0.066 & 0.424 & 27.678 & 0.026 & 0.042 & 0.052 \\
FI & 0.046 & 0.081 & 0.424 & 0.024 & 0.039 & 0.049 \\
FR & 0.069 & 0.314 & 6.327 & 0.028 & 0.044 & 0.054 \\
GR & 0.048 & 0.070 & 0.371 & 0.026 & 0.041 & 0.052 \\
IT & 0.054 & 0.077 & 0.183 & 0.027 & 0.043 & 0.053 \\
LU & 0.070 & 0.187 & 0.984 & 0.029 & 0.044 & 0.054 \\
MT & 0.033 & 0.028 & 0.041 & 0.020 & 0.033 & 0.042 \\
NL & 0.028 & 0.016 & 0.014 & 0.019 & 0.032 & 0.042 \\
PT & 0.072 & 0.173 & 1.099 & 0.032 & 0.049 & 0.060 \\
SI & 0.038 & 0.039 & 0.064 & 0.022 & 0.036 & 0.046 \\
SK & 0.047 & 0.096 & 0.503 & 0.024 & 0.038 & 0.049 \\
\hline So & 0.045 & & & &
\end{tabular}

Source: HFCS, authors` own calculations. The initial cut-off is top 90\% quantile 
Table A.4: One Dimensional Affluence Measures for Top 90\%:

Wealth

\begin{tabular}{ccccccc}
\hline & $\boldsymbol{R}_{\boldsymbol{\alpha}=\mathbf{1}}^{M}$ & $\boldsymbol{R}_{\boldsymbol{\alpha}=\mathbf{2}}^{M}$ & $\boldsymbol{R}_{\boldsymbol{\alpha}=\mathbf{3}}^{M}$ & $\boldsymbol{R}_{\boldsymbol{\beta}=\mathbf{1}}^{M}$ & $\boldsymbol{R}_{\boldsymbol{\beta}=\mathbf{2}}^{M}$ & $\boldsymbol{R}_{\boldsymbol{\beta}=\mathbf{3}}^{M}$ \\
\hline AT & 0.200 & 2.019 & 43.151 & 0.044 & 0.061 & 0.070 \\
BE & 0.112 & 0.375 & 2.104 & 0.038 & 0.055 & 0.065 \\
CY & 0.161 & 0.989 & 14.462 & 0.043 & 0.061 & 0.071 \\
DE & 0.161 & 1.925 & 66.871 & 0.038 & 0.054 & 0.064 \\
ES & 0.108 & 3.561 & 1583.581 & 0.034 & 0.051 & 0.061 \\
FI & 0.083 & 0.382 & 6.490 & 0.032 & 0.049 & 0.059 \\
FR & 0.128 & 2.438 & 269.965 & 0.037 & 0.055 & 0.065 \\
GR & 0.072 & 0.134 & 0.541 & 0.032 & 0.050 & 0.060 \\
IT & 0.114 & 0.593 & 8.610 & 0.036 & 0.054 & 0.064 \\
LU & 0.169 & 1.512 & 23.863 & 0.038 & 0.054 & 0.063 \\
MT & 0.145 & 3.066 & 123.808 & 0.034 & 0.051 & 0.062 \\
NL & 0.060 & 0.102 & 0.395 & 0.029 & 0.045 & 0.056 \\
PT & 0.171 & 3.457 & 226.696 & 0.040 & 0.057 & 0.066 \\
SI & 0.072 & 0.123 & 0.328 & 0.033 & 0.050 & 0.061 \\
SK & 0.072 & 0.145 & 0.480 & 0.031 & 0.048 & 0.058 \\
\hline So & 0.065 & & & &
\end{tabular}

Source: HFCS, authors` own calculations. The initial cut-off is top 90\% quantile 
Table A.5: One Dimensional Affluence Measures for Top 99\%:

Income

\begin{tabular}{ccccccc}
\hline & $\boldsymbol{R}_{\boldsymbol{\alpha}=\mathbf{1}}^{M}$ & $\boldsymbol{R}_{\boldsymbol{\alpha}=\mathbf{2}}^{M}$ & $\boldsymbol{R}_{\boldsymbol{\alpha}=\mathbf{3}}^{M}$ & $\boldsymbol{R}_{\boldsymbol{\beta}=\mathbf{1}}^{M}$ & $\boldsymbol{R}_{\boldsymbol{\beta}=\mathbf{2}}^{M}$ & $\boldsymbol{R}_{\boldsymbol{\beta}=\mathbf{3}}^{M}$ \\
\hline AT & 0.006 & 0.009 & 0.017 & 0.003 & 0.004 & 0.005 \\
BE & 0.008 & 0.033 & 0.220 & 0.003 & 0.004 & 0.005 \\
CY & 0.010 & 0.017 & 0.037 & 0.004 & 0.006 & 0.007 \\
DE & 0.005 & 0.007 & 0.015 & 0.002 & 0.004 & 0.005 \\
ES & 0.011 & 0.065 & 2.301 & 0.004 & 0.005 & 0.006 \\
FI & 0.005 & 0.009 & 0.032 & 0.002 & 0.004 & 0.005 \\
FR & 0.008 & 0.033 & 0.331 & 0.003 & 0.005 & 0.006 \\
GR & 0.004 & 0.006 & 0.026 & 0.002 & 0.003 & 0.004 \\
IT & 0.003 & 0.002 & 0.002 & 0.002 & 0.003 & 0.004 \\
LU & 0.008 & 0.013 & 0.028 & 0.003 & 0.005 & 0.006 \\
MT & 0.004 & 0.002 & 0.002 & 0.002 & 0.004 & 0.005 \\
NL & 0.002 & 0.001 & 0.000 & 0.002 & 0.003 & 0.004 \\
PT & 0.006 & 0.011 & 0.037 & 0.003 & 0.004 & 0.005 \\
SI & 0.004 & 0.003 & 0.002 & 0.003 & 0.004 & 0.006 \\
SK & 0.007 & 0.014 & 0.042 & 0.003 & 0.004 & 0.005 \\
\hline So6 & 0.005
\end{tabular}

Source: HFCS, authors` own calculations. The initial cut-off is top 99\% quantile 
Table A.6: One Dimensional Affluence Measures for Top 99\%:

Wealth

\begin{tabular}{ccccccc}
\hline & $\boldsymbol{R}_{\boldsymbol{\alpha}=\mathbf{1}}^{M}$ & $\boldsymbol{R}_{\boldsymbol{\alpha}=\mathbf{2}}^{M}$ & $\boldsymbol{R}_{\boldsymbol{\alpha}=\mathbf{3}}^{M}$ & $\boldsymbol{R}_{\boldsymbol{\beta}=\mathbf{1}}^{M}$ & $\boldsymbol{R}_{\boldsymbol{\beta}=\mathbf{2}}^{M}$ & $\boldsymbol{R}_{\boldsymbol{\beta}=\mathbf{3}}^{\boldsymbol{M}}$ \\
\hline AT & 0.011 & 0.033 & 0.137 & 0.004 & 0.006 & 0.007 \\
BE & 0.005 & 0.005 & 0.006 & 0.003 & 0.004 & 0.005 \\
CY & 0.006 & 0.014 & 0.052 & 0.002 & 0.003 & 0.004 \\
DE & 0.015 & 0.067 & 0.614 & 0.004 & 0.006 & 0.007 \\
ES & 0.014 & 0.356 & 55.130 & 0.003 & 0.005 & 0.006 \\
FI & 0.008 & 0.031 & 0.240 & 0.003 & 0.005 & 0.006 \\
FR & 0.014 & 0.172 & 6.029 & 0.004 & 0.005 & 0.006 \\
GR & 0.004 & 0.004 & 0.010 & 0.002 & 0.003 & 0.004 \\
IT & 0.008 & 0.021 & 0.104 & 0.003 & 0.005 & 0.006 \\
LU & 0.014 & 0.037 & 0.118 & 0.005 & 0.006 & 0.007 \\
MT & 0.030 & 0.385 & 5.799 & 0.004 & 0.005 & 0.006 \\
NL & 0.004 & 0.005 & 0.011 & 0.002 & 0.003 & 0.004 \\
PT & 0.016 & 0.159 & 2.657 & 0.004 & 0.005 & 0.006 \\
SI & 0.003 & 0.002 & 0.002 & 0.002 & 0.004 & 0.004 \\
SK & 0.004 & 0.003 & 0.003 & 0.002 & 0.004 & 0.005 \\
\hline S0ure & & & &
\end{tabular}

Source: HFCS, authors' own calculations. The initial cut-off is top 99\% quantile 
Figure A.4: Comparison of Convex Multidimensional Affluence Measures for k=1

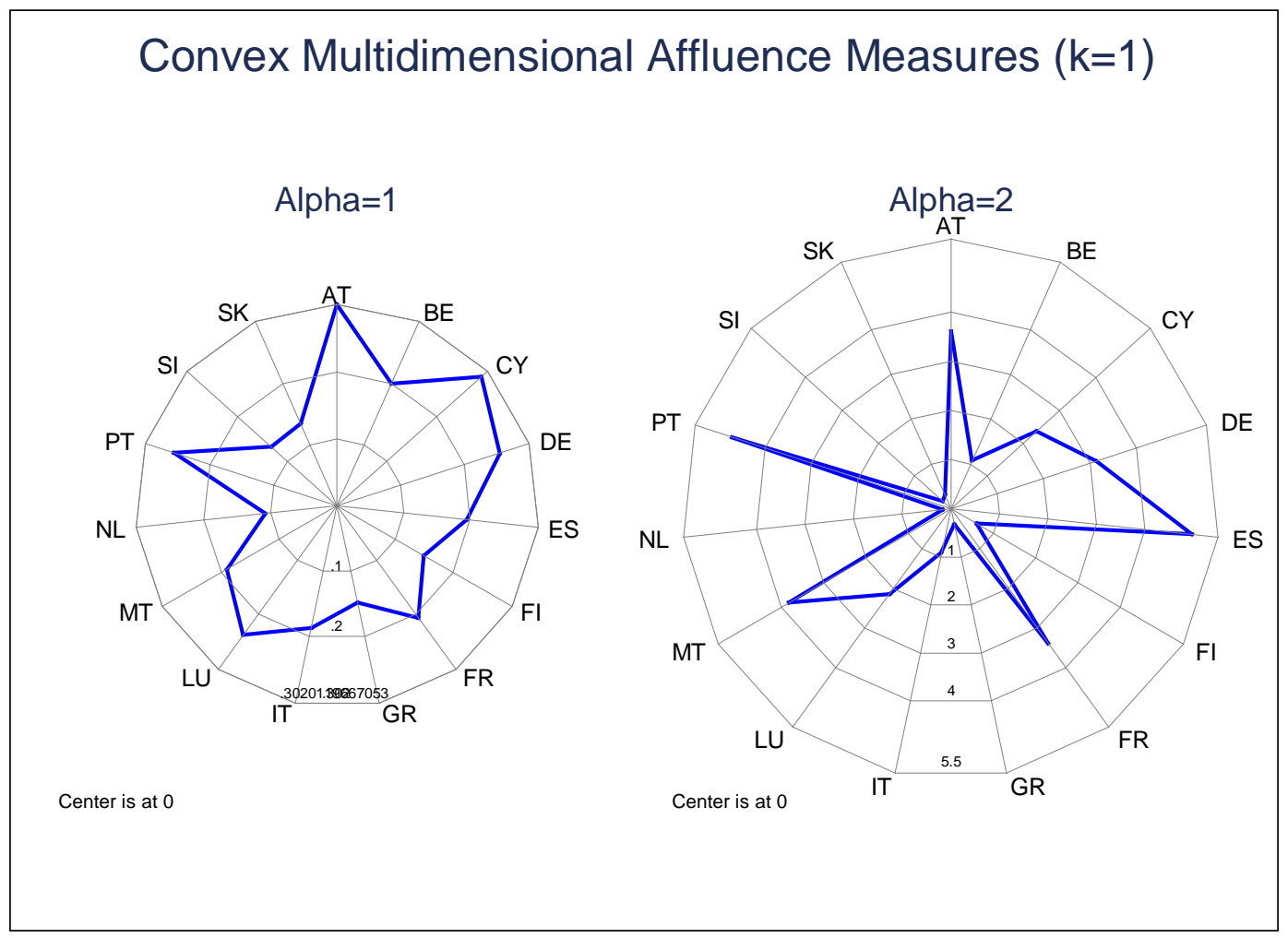

Figure A.5: Comparison of Concave Multidimensional Affluence Measures for $\mathrm{k}=1$

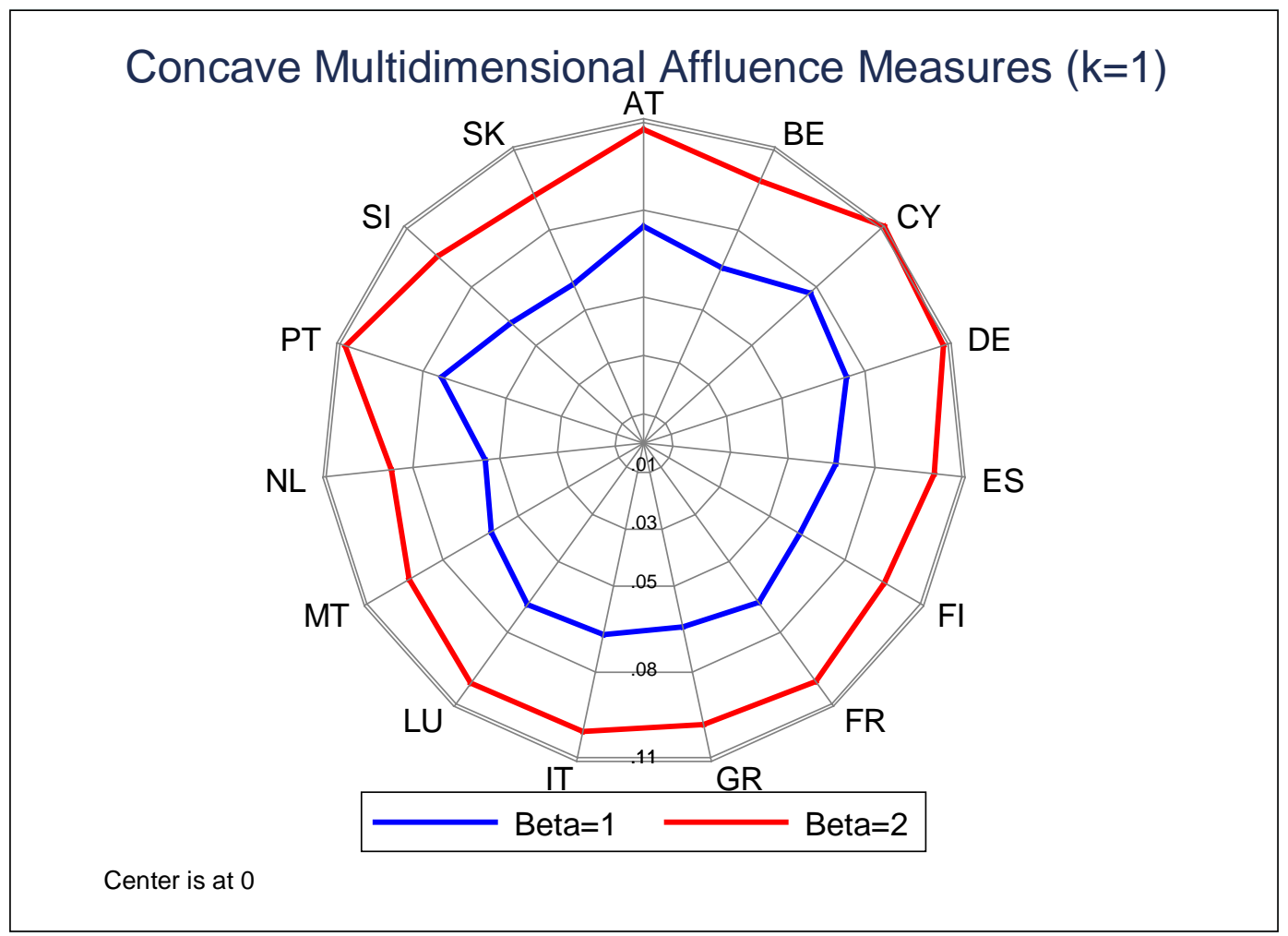


Table A.7. Multidimensional Measures of Affluence for Top 90\%

Second Cut-

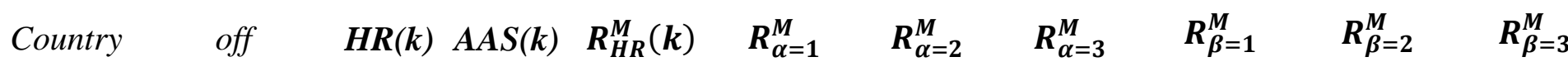

\begin{tabular}{|c|c|c|c|c|c|c|c|c|c|c|}
\hline & $\mathrm{k}=1$ & 0.165 & 0.605 & 0.100 & 0.138 & 0.037 & 1.115 & 0.053 & 22.141 & 0.063 \\
\hline \multirow[t]{2}{*}{ AT } & $\mathrm{k}=2$ & 0.035 & 1 & 0.035 & 0.068 & 0.016 & 0.513 & 0.022 & 8.741 & 0.025 \\
\hline & $\mathrm{k}=1$ & 0.170 & 0.586 & 0.100 & 0.106 & 0.035 & 0.512 & 0.051 & 7.409 & 0.061 \\
\hline \multirow[t]{2}{*}{ BE } & $\mathrm{k}=2$ & 0.029 & 1 & 0.029 & 0.036 & 0.011 & 0.129 & 0.016 & 0.738 & 0.019 \\
\hline & $\mathrm{k}=1$ & 0.166 & 0.597 & 0.099 & 0.114 & 0.035 & 0.596 & 0.051 & 7.794 & 0.061 \\
\hline \multirow[t]{2}{*}{ CY } & $\mathrm{k}=2$ & 0.032 & 1 & 0.032 & 0.057 & 0.013 & 0.369 & 0.018 & 4.023 & 0.021 \\
\hline & $\mathrm{k}=1$ & 0.159 & 0.628 & 0.100 & 0.111 & 0.033 & 1.017 & 0.050 & 33.657 & 0.060 \\
\hline \multirow[t]{2}{*}{ DE } & $\mathrm{k}=2$ & 0.041 & 1 & 0.041 & 0.063 & 0.016 & 0.613 & 0.024 & 22.998 & 0.028 \\
\hline & $\mathrm{k}=1$ & 0.160 & 0.622 & 0.100 & 0.087 & 0.030 & 1.992 & 0.046 & 805.630 & 0.056 \\
\hline \multirow[t]{2}{*}{ ES } & $\mathrm{k}=2$ & 0.039 & 1 & 0.039 & 0.055 & 0.015 & 0.697 & 0.022 & 47.690 & 0.026 \\
\hline & $\mathrm{k}=1$ & 0.159 & 0.630 & 0.100 & 0.064 & 0.028 & 0.231 & 0.044 & 3.457 & 0.054 \\
\hline \multirow[t]{2}{*}{ FI } & $\mathrm{k}=2$ & 0.041 & 1 & 0.041 & 0.042 & 0.015 & 0.209 & 0.022 & 3.412 & 0.027 \\
\hline & $\mathrm{k}=1$ & 0.154 & 0.650 & 0.100 & 0.099 & 0.033 & 1.376 & 0.049 & 138.146 & 0.060 \\
\hline \multirow[t]{2}{*}{ FR } & $\mathrm{k}=2$ & 0.046 & 1 & 0.046 & 0.071 & 0.019 & 1.243 & 0.027 & 129.459 & 0.032 \\
\hline & $\mathrm{k}=1$ & 0.166 & 0.602 & 0.100 & 0.060 & 0.029 & 0.102 & 0.046 & 0.456 & 0.056 \\
\hline \multirow[t]{2}{*}{ GR } & $\mathrm{k}=2$ & 0.034 & 1 & 0.034 & 0.027 & 0.012 & 0.061 & 0.018 & 0.367 & 0.021 \\
\hline & $\mathrm{k}=1$ & 0.155 & 0.643 & 0.100 & 0.084 & 0.032 & 0.335 & 0.048 & 4.396 & 0.058 \\
\hline \multirow[t]{2}{*}{ IT } & $\mathrm{k}=2$ & 0.044 & 1 & 0.044 & 0.056 & 0.018 & 0.284 & 0.026 & 4.170 & 0.030 \\
\hline & $\mathrm{k}=1$ & 0.163 & 0.615 & 0.100 & 0.119 & 0.033 & 0.850 & 0.049 & 12.424 & 0.058 \\
\hline \multirow[t]{2}{*}{$\mathbf{L U}$} & $\mathrm{k}=2$ & 0.037 & 1 & 0.037 & 0.067 & 0.014 & 0.666 & 0.020 & 11.179 & 0.024 \\
\hline & $\mathrm{k}=1$ & 0.167 & 0.583 & 0.097 & 0.089 & 0.027 & 1.547 & 0.042 & 61.925 & 0.052 \\
\hline \multirow[t]{2}{*}{ MT } & $\mathrm{k}=2$ & 0.028 & 1 & 0.028 & 0.058 & 0.010 & 1.515 & 0.015 & 61.874 & 0.017 \\
\hline & $\mathrm{k}=1$ & 0.176 & 0.565 & 0.100 & 0.044 & 0.024 & 0.059 & 0.039 & 0.204 & 0.049 \\
\hline \multirow[t]{2}{*}{ NL } & $\mathrm{k}=2$ & 0.023 & 1 & 0.023 & 0.015 & 0.007 & 0.028 & 0.011 & 0.118 & 0.013 \\
\hline & $\mathrm{k}=1$ & 0.159 & 0.628 & 0.100 & 0.121 & 0.036 & 1.815 & 0.053 & 113.898 & 0.063 \\
\hline \multirow[t]{2}{*}{ PT } & $\mathrm{k}=2$ & 0.041 & 1 & 0.041 & 0.077 & 0.018 & 1.645 & 0.025 & 110.993 & 0.029 \\
\hline & $\mathrm{k}=1$ & 0.166 & 0.586 & 0.097 & 0.055 & 0.027 & 0.081 & 0.043 & 0.196 & 0.054 \\
\hline \multirow[t]{2}{*}{ SI } & $\mathrm{k}=2$ & 0.029 & 1 & 0.029 & 0.025 & 0.010 & 0.049 & 0.016 & 0.136 & 0.019 \\
\hline & $\mathrm{k}=1$ & 0.172 & 0.581 & 0.100 & 0.060 & 0.027 & 0.121 & 0.043 & 0.491 & 0.053 \\
\hline SK & $\mathrm{k}=2$ & 0.028 & 1 & 0.028 & 0.023 & 0.010 & 0.048 & 0.015 & 0.169 & 0.018 \\
\hline
\end{tabular}


Table A.8. Multidimensional Measures of Affluence for Top 99\%

Second Cut-

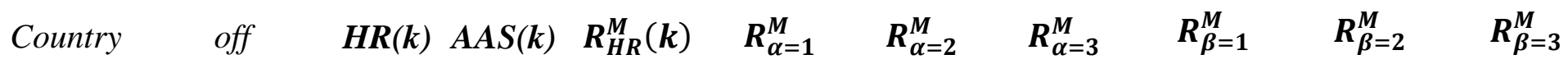

\begin{tabular}{|c|c|c|c|c|c|c|c|c|c|c|}
\hline \multirow{2}{*}{ AT } & $\mathrm{k}=1$ & 0.019 & 0.520 & 0.010 & 0.009 & 0.003 & 0.021 & 0.005 & 0.077 & 0.006 \\
\hline & $\mathrm{k}=2$ & 0.001 & 1 & 0.001 & 0.000 & 0.000 & 0.001 & 0.000 & 0.001 & 0.000 \\
\hline \multirow{2}{*}{ BE } & $\mathrm{k}=1$ & 0.019 & 0.522 & 0.010 & 0.007 & 0.003 & 0.019 & 0.004 & 0.113 & 0.005 \\
\hline & $k=2$ & 0.001 & 1 & 0.001 & 0.000 & 0.000 & 0.000 & 0.000 & 0.000 & 0.000 \\
\hline \multirow{2}{*}{$\mathbf{C Y}$} & $\mathrm{k}=1$ & 0.016 & 0.564 & 0.009 & 0.008 & 0.003 & 0.016 & 0.005 & 0.045 & 0.005 \\
\hline & $\mathrm{k}=2$ & 0.002 & 1 & 0.002 & 0.003 & 0.001 & 0.005 & 0.002 & 0.010 & 0.002 \\
\hline \multirow{2}{*}{ DE } & $\mathrm{k}=1$ & 0.018 & 0.567 & 0.010 & 0.010 & 0.003 & 0.037 & 0.005 & 0.315 & 0.006 \\
\hline & $\mathrm{k}=2$ & 0.002 & 1 & 0.002 & 0.003 & 0.001 & 0.012 & 0.001 & 0.176 & 0.002 \\
\hline \multirow{2}{*}{ ES } & $\mathrm{k}=1$ & 0.017 & 0.595 & 0.010 & 0.012 & 0.004 & 0.210 & 0.005 & 28.715 & 0.006 \\
\hline & $\mathrm{k}=2$ & 0.003 & 1 & 0.003 & 0.007 & 0.001 & 0.067 & 0.002 & 2.172 & 0.002 \\
\hline \multirow{2}{*}{ FI } & $\mathrm{k}=1$ & 0.016 & 0.612 & 0.010 & 0.007 & 0.003 & 0.020 & 0.004 & 0.136 & 0.005 \\
\hline & $k=2$ & 0.004 & 1 & 0.004 & 0.005 & 0.001 & 0.018 & 0.002 & 0.134 & 0.002 \\
\hline \multirow{2}{*}{ FR } & $\mathrm{k}=1$ & 0.016 & 0.630 & 0.010 & 0.011 & 0.003 & 0.102 & 0.005 & 3.180 & 0.006 \\
\hline & $\mathrm{k}=2$ & 0.004 & 1 & 0.004 & 0.008 & 0.002 & 0.090 & 0.003 & 2.967 & 0.003 \\
\hline \multirow{2}{*}{ GR } & $\mathrm{k}=1$ & 0.018 & 0.531 & 0.010 & 0.004 & 0.002 & 0.005 & 0.003 & 0.018 & 0.004 \\
\hline & $\mathrm{k}=2$ & 0.001 & 1 & 0.001 & 0.001 & 0.000 & 0.002 & 0.001 & 0.014 & 0.001 \\
\hline \multirow{2}{*}{ IT } & $\mathrm{k}=1$ & 0.017 & 0.586 & 0.010 & 0.006 & 0.003 & 0.012 & 0.004 & 0.053 & 0.005 \\
\hline & $k=2$ & 0.003 & 1 & 0.003 & 0.002 & 0.001 & 0.005 & 0.001 & 0.037 & 0.002 \\
\hline \multirow{2}{*}{$\mathbf{L U}$} & $\mathrm{k}=1$ & 0.017 & 0.596 & 0.010 & 0.011 & 0.004 & 0.025 & 0.006 & 0.073 & 0.007 \\
\hline & $\mathrm{k}=2$ & 0.003 & 1 & 0.003 & 0.005 & 0.001 & 0.013 & 0.002 & 0.046 & 0.002 \\
\hline \multirow{2}{*}{ MT } & $\mathrm{k}=1$ & 0.017 & 0.593 & 0.010 & 0.017 & 0.003 & 0.194 & 0.005 & 2.900 & 0.006 \\
\hline & $k=2$ & 0.003 & 1 & 0.003 & 0.003 & 0.001 & 0.005 & 0.002 & 0.009 & 0.002 \\
\hline \multirow{2}{*}{ NL } & $\mathrm{k}=1$ & 0.018 & 0.540 & 0.010 & 0.003 & 0.002 & 0.003 & 0.003 & 0.006 & 0.004 \\
\hline & $\mathrm{k}=2$ & 0.001 & 1 & 0.001 & 0.001 & 0.000 & 0.001 & 0.001 & 0.003 & 0.001 \\
\hline \multirow{2}{*}{ PT } & $\mathrm{k}=1$ & 0.017 & 0.573 & 0.010 & 0.011 & 0.003 & 0.085 & 0.005 & 1.347 & 0.006 \\
\hline & $\mathrm{k}=2$ & 0.003 & 1 & 0.003 & 0.006 & 0.001 & 0.073 & 0.002 & 1.290 & 0.002 \\
\hline \multirow{2}{*}{ SI } & $\mathrm{k}=1$ & 0.018 & 0.517 & 0.009 & 0.004 & 0.002 & 0.002 & 0.004 & 0.002 & 0.005 \\
\hline & $\mathrm{k}=2$ & 0.001 & 1 & 0.001 & 0.000 & 0.000 & 0.000 & 0.000 & 0.001 & 0.000 \\
\hline \multirow{2}{*}{ SK } & $\mathrm{k}=1$ & 0.019 & 0.531 & 0.010 & 0.005 & 0.003 & 0.008 & 0.004 & 0.022 & 0.005 \\
\hline & $\mathrm{k}=2$ & 0.001 & 1 & 0.001 & 0.001 & 0.000 & 0.001 & 0.001 & 0.001 & 0.001 \\
\hline
\end{tabular}




\section{References:}

Alkire, S. and Foster, J. (2011): Counting and multidimensional poverty measurement, Journal of Public Economics, 95, 467-87.

Andreasch M. and Linder P. (2014) "Micro and Macro Data A Comparison of the Household Finance and Consumption Survey with Financial Accounts in Austria" ECB Working Paper Series, no. 1673/ May.

Arrondel, L., Roger, M. and Savignac, F. (2014): Wealth and income in the Euro area: Heterogeneity in households' behaviours. ECB Working Paper Series, no.1709/August.

Atkinson, A. B. (2003): Multidimensional deprivation: contrasting social welfare and counting approaches, Journal of Economic Inequality, 1, 51-65.

Atkinson, A. B. (2005) "Comparing the Distribution of Top Incomes Across Countries," Journal of the European Economic Association, MIT Press, vol. 3(2-3), 393-401, 04/05.

Atkinson, A. B. and Piketty, T. (2007): Top incomes over the twentieth century. Oxford University Press, Oxford.

Atkinson, A. B., T. Piketty, and E. Saez (2011). Top Incomes in the Long Run of History. Journal of Economic Literature 49 (1), 3-71.

Brauninger D. (2012) "Income and wealth taxes in the Euro area” Research Briefing, Deutsche Bank

Bourguignon, F., and S. R. Chakravarty (2003): The Measurement of Multidimensional Poverty," Journal of Economic Inequality, 1, 25-49.

Caju, P. D. (2013) Structure and distribution of household wealth: an analysis based on HFCS. National Bank of Belgium Economic Review.

D'Alessio G., Gambacorta R., Ilardi G. (2013) “Are Germans poorer than other Europeans? The principal Eurozone differences in wealth and income“ VoxEU.org, 24 May.

Decancq, K. and M. A. Lugo (2011a). Inequality of Well-Being: A Multidimensional Approach. Economica forthcoming.

Decancq, K. and M. A. Lugo (2011b). Weights in Multidimensional Well-Being: An Overview. Econometric Reviews forthcoming.

Decancq, K. and E. Ooghe (2010). Has the World Moved Forward? A Robust Multidimensional Evaluation. Economics Letters 107 (2), 266-269.

Eurosystem Household Finance and Consumption Network (2013a) The Eurosystem household finance and consumption survey: methodological report for the first wave, ECB Statistical Paper Series, No.1

Eurosystem Household Finance and Consumption Network (2013b) The Eurosystem household finance and consumption survey:results from the first wave, ECB Statistical Paper Series, No.2 
Eurosystem Household Finance and Consumption Network (2013c) HFCS Country Surveys Metadata Information, Doc.UDB5, ECB.

Foster,J., Greer, J. and Thorbecke, E. (1984) "A class of decomposable poverty measures" Econometrica, vol. 52, pp.761-766.

Fessler, P., Linder, P., Segalla, E. (2014) "Net Wealth across the Euroarea - why household structure matters and how to control for it", ECB Working Paper Series, no.1663/April.

Fessler P. and Schurz M. (2013) "Cross-Country Comparability of the Eurosystem Household Finance and Consumption Survey" Monetary Policy and the Economy, Austrian Central Bank, Q2/13, pp.29-50.

Honkkila J. and Kavanius K. (2013) "Micro and Macro Analysis on Household Income, Wealth and Saving in the Euro Area", ECB Working Paper Series, no.1619/November.

Jenkins S.P., Jantti M. (2005) "Methods for summarizing and comparing wealth distributions" ISER Working Paper 2005-05, Institute for Social and Economic Research, University of Essex, Colchester, UK.

Kopczuk, W. \& Saez, E. (2004) "Top Wealth Shares in the United States, 1916-2000: Evidence from Estate Tax Returns," National Tax Journal, National Tax Association, vol. 57(2), 445-87.

Peichl, A. and Pestel, N. (2013a) "Multidimensional affluence: theory and applications to Germany and the US", Applied Economics, 45:32, 4591-4601.

Peichl, A. and Pestel, N. (2013b) Multidimensional well-being at the top: Evidence for Germany, Fiscal Studies, vol.34:3, pp.355-371.

Peichl, A. Schaefer, T. and Scheicher, C. (2010) Measuring richness and poverty: a microdata application to Europe and Germany. Review of Income and Wealth, 56, 597-619.

Piketty T., (2005) "Top Income Shares in the Long Run: An Overview," Journal of the European Economic Association, MIT Press, vol. 3(2-3), pages 382-392, 04/05

Piketty T. \& Saez, E. (2006) "The Evolution of Top Incomes: A Historical and International Perspective," American Economic Review, American Economic Association, vol. 96(2), 200205.

Piketty T. (2013) "Wealth and nheritance in the Long Run" Handbook of Income Distribution, Vol. 2B, Chapter 15, Paris, ISSN 1574-0056

Roine, J. \& Waldenstrom, D. (2008) "The evolution of top incomes in an egalitarian society: Sweden, 1903-2004," Journal of Public Economics, Elsevier, vol. 92(1-2), 366-387.

Roine, Jesper \& Vlachos, Jonas \& Waldenström, Daniel, 2009. "The long-run determinants of inequality: What can we learn from top income data?," Journal of Public Economics, Elsevier, vol. 93(7-8), pages 974-988.

Roine J. \& Waldenström D., (2011) "Common Trends and Shocks to Top Incomes: A Structural Breaks Approach," The Review of Economics and Statistics, MIT Press, vol. 93(3), 832-846. 
Saez E., (2005) "Top Incomes in the United States and Canada Over the Twentieth Century," Journal of the European Economic Association, MIT Press, vol. 3(2-3), pages 402-411, 04/05.

Tiefensee A. and Grabka M.M. (2014) "Comparing Wealth - Data Quality of the HFCS" DIW Discussion Papers 1427

Vermeulen, P. (2014) How fat is the top tail of the wealth distribution. ECB Working Paper Series, No. 1692/ July.

Waldenström D. (2009) Lifting All Boats? The Evolution of Income and Wealth Inequality over the Path of Develoment, Lund Studies in Economic History no.51, Lund: Media-Tryck, Lunds University. 